\title{
Telomere as an Important Player in Regulation of Microbial Pathogen Virulence
}

\author{
Bibo Li \\ Cleveland State University \\ USA
}

\section{Introduction}

Telomeres are nucleoprotein complexes located at the ends of linear chromosomes. In most eukaryotic cells, telomere DNA consists of simple repetitive TG-rich sequences, with the TG-rich strand running $5^{\prime}$ to $3^{\prime}$ towards the chromosome ends. Telomere DNA contains both the duplex region and a 3' G-rich single-stranded overhang at the very end. In human, mouse, a hypotrichous ciliate, and trypanosomes, the single-stranded telomere G-overhang invades the double-stranded region and forms a T-loop structure (Griffith et al. 1999; Munoz-Jordan et al. 2001; Murti \& Prescott 1999; Nikitina \& Woodcock 2004), which has been proposed to play an important role in chromosome end protection (de Lange 2002).

A number of proteins have been identified to specifically associate with the telomere DNA, and this telomere complex appears to be largely conserved from protozoa to mammals. The telomere protein complex termed "Shelterin" is well characterized in mammalian cells (Fig. 1) (de Lange 2005). Within the complex, TTAGGG Repeat binding Factor 1 (TRF1) and TRF2 are duplex telomere DNA binding factors (Bilaud et al. 1997; Broccoli et al. 1997; Chong et al. 1995), Protection of Telomeres 1 (POT1) is a single-stranded telomere DNA binding factor (Baumann \& Cech 2001), while Repressor Activator Protein 1 (RAP1) (Li et al. 2000), TRF1Interacting Nuclear factor 2 (TIN2) (Kim et al. 1999), and TPP1 (previously known as POT1interacting protein PIP1 (Ye et al. 2004), TIN2 interacting protein TINT1 (Houghtaling et al. 2004), or POT1- and TIN2-interacting factor PTOP (Liu et al. 2004)) do not directly contact telomere DNA but tightly associate with TRFs or POT1. Very recently, a trimeric CST complex containing Conserved Telomere maintenance Component 1 (CTC1), STN1, and TEN1 have also been identified in human cells to bind the single-stranded telomere DNA (Miyake et al. 2009; Wan et al. 2009).

In fission yeast Schizosaccharomyces pombe, SpTaz1 (a TRF homolog), SpRap1, SpPot1, SpPoz1 (a TIN2 homolog), SpTpz1 (a TPP1 homolog), SpTen1, and SpStn1 have been identified (Fig. 1 ), and the complex is very similar to that in mammalian cells (Dehe \& Cooper 2010). Recent studies in our lab has led to the identification of TRF (Li et al. 2005), RAP1 (Yang et al. 2009), and TIN2 (Jehi S. \& Li B., unpublished data) homologues in Trypanosoma brucei, a protozoan parasite belongs to the kinetoplastids group (Fig. 1), although no specific single-stranded telomere DNA binding proteins has been identified in this organism. These studies indicated that the TRF-RAP1-TIN2-TPP1-POT1 complex is at least partially conserved from protozoan to mammalian cells. However, the telomere complex in budding yeast 
Saccharomyces cerevisiae is much less conserved (Fig. 1). ScRap1, instead of a TRF homolog, binds the duplex telomere DNA (Longtine et al. 1989b), while TIN2, TPP1, and POT1 homologs appear to have been lost, and the ScCdc13/ScTen1/ScStn1 complex binds the single-stranded telomere DNA (Grandin et al. 1997, 2001; Nugent et al. 1996).
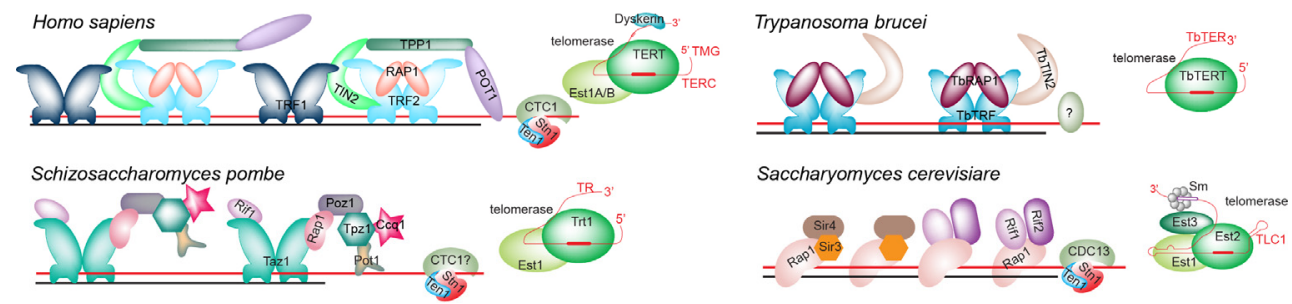

Fig. 1. The telomere complexes in human cells, budding and fission yeasts, and a protozoan parasite, Trypanosoma brucei. Proteins specifically associate with the telomeres are shown and marked. The telomerase holoenzyme is also shown. In human cells, TERT and TERC are the protein and the RNA component, respectively. Est1A/B is part of the holoenzyme, while Dyskerin interacts with TERC and plays an important role for TERC maturation. The telomerase (Trt1 and TR) and its associated Est1 has been identified in S. pombe. In $S$. cerevisiae, the core telomerase (Est2 and TLC1) is associated with Est1 and Est3, while TLC1 interacts with Sm proteins to maintain its stability.

Telomeres have two essential functions. First, binding of telomere proteins masks the natural chromosome ends so that telomeres are not recognized as DNA double strand breaks (DSB) and are protected from illegitimate DNA degradation, repair, and recombination processes (Stewart et al. 2011). Hence, the telomere structure is essential for genome integrity. Second, conventional DNA polymerases are incapable of fully replicate the ends of linear DNA molecules, and telomeres are expected to shorten progressively after each round of DNA replication (Levy et al. 1992). Fortunately, a specialized reverse transcriptase called telomerase can synthesize de novo the telomere G-rich strand DNA according to its internal RNA template and effectively solve this "end replication problem" (Greider \& Blackburn 1987; Zvereva et al. 2010). Both chromosome end protection and telomere maintenance are complicated processes and are regulated at multiple levels. For more comprehensive reviews on these topics, please refer to (Cifuentes-Rojas \& Shippen 2011; Palm \& de Lange 2008; Stewart et al. 2011)

It is worth to point out that recombination mechanisms can be activated to maintain the telomere length when telomerase is absent in many organisms including yeasts and mammals (Bryan et al. 1995; Hande et al. 1999; Lendvay et al. 1996; Lundblad \& Szostak 1989; Nabetani \& Ishikawa 2011; Niida et al. 2000; Singer \& Gottschling 1994). In S. cerevisiae, when telomerase is dysfunctional, a RAD51-dependent recombination pathway can amplify the subtelomeric $Y^{\prime}$ element to generate Type I survivors (Le et al. 1999; Teng \& Zakian 1999), and a RAD50dependent recombination pathway can amplify the telomere repeats to give rise to Type II survivors (Le et al. 1999; Lundblad \& Blackburn 1993; McEachern \& Blackburn 1996; Teng \& Zakian 1999; Teng et al. 2000). Both pathways depend on RAD52, indicating that recommendation events are involved. In $\sim 10 \%$ of human tumor cells, telomeres are maintained by a telomerase-independent mechanisms termed ALT (Reddel et al. 1997). In the ALT cells, telomere lengths are typically very heterogeneous, ranging from $<3 \mathrm{~kb}$ to $>50 \mathrm{~kb}$ (Bryan et al. 
1995, 1997; Grobelny et al. 2000; Murnane et al. 1994; Opitz et al. 2001). Telomere maintenance in ALT cells appears to also involve recombination between different telomeres: when a plasmid tag was targeted into a telomere in a clonal ALT cell, with increasing population doubling, a progressive increase in the number of chromosomes containing the tagged telomeres was observed by FISH analysis (Dunham et al. 2000). Using a Chromosome Oriented-FISH (COFISH) analysis (Bailey et al. 2001), a detailed analysis of a number of mortal cell strains, in vitro immortalized cell lines, and cancer-derived cell lines showed that postreplicative exchanges involving a telomere and another TTAGGG-repeat tract occurred frequently in ALT cells but only rarely or never in non-ALT cells (Bailey et al. 2004; Londono-Vallejo et al. 2004), further suggesting that telomere recombination is a main pathway for telomere maintenance in ALT cells. In addition, one unusual telomere maintenance has been observed in telomerase negative Trypanosoma brucei cells (Dreesen \& Cross 2006b). At least for a subset of telomeres that are marked with subtelomeric silent VSG expression sites (see below), the telomere can be as short as $\sim 40 \mathrm{bp}$. Yet, these telomeres can be maintained stably for several tens of population doublings. However, the underlying mechanism is completely unknown.

\section{Telomere position effect (TPE)}

\subsection{The phenomenon of TPE}

Telomere position effect or TPE has been observed in a number of organisms, where the telomere structure exerts a variegated repressive effect on the transcription of genes located at subtelomeric regions.

TPE was first observed in D. melanogaster as a phenomenon of position effect variegation $(\mathrm{PEV})$, which is a silencing effect on a gene located near a heterochromatic region in general (Gehring et al. 1984; Hazelrigg et al. 1984; Levis et al. 1985). A few years later, TPE was observed in S. cerevisiae (Gottschling et al. 1990): When a URA3 marker together with a short $\mathrm{TG}_{1-3}$ telomere seed sequence is inserted to the left arm of chromosome VII at the subtelomeric region, the original VII-L telomere breaks off, and a new telomere forms from the seed $\sim 1.1 \mathrm{~kb}$ from the URA3 transcription starting site. This URA3 gene can be expressed, allowing cells to grow on uracil lacking medium, but it can also be suppressed, allowing cells to grow on 5-FOA-containing medium (5-FOA will be converted to a toxic compound by the functional URA3 gene product). Therefore, the silencing effect is variegated and its regulation appears to be epigenetic. Similarly, a subtelomeric ADE2 marker can be either expressed (colonies are white when growing on low adenine medium) or silenced (colonies are red). In addition, the transcriptional state is quite stable, inheritable for a number of generations, giving rise to yeast colonies with red and white sectors.

A fundamental aspect of TPE is position dependent, which reflects that the silencing machinery works in a cis-acting fashion - association of the machinery with the telomere is necessary for an effect on subtelomeric genes. Studies in several organisms revealed a common theme: telomere DNA is the anchor, and one or two telomere binding proteins would recruit the silencing machinery to the telomere to establish TPE.

\subsection{TPE in S. cerevisiae}

Extensive studies in the last couple of decades have led to a fairly good understanding of TPE in S. cerevisiae. One of the key players for TPE in S. cerevisiae is Rap1 (Kyrion et al. 1993), 
which binds telomere DNA directly (Giraldo \& Rhodes 1994; Konig et al. 1996; Longtine et al. 1989a) and recruits Sir3 and Sir4 silencers to the telomere through its C-terminal RCT domain (Buck \& Shore 1995; Chen et al. 2011; Cockell et al. 1995; Feeser \& Wolberger 2008; Hecht et al. 1996; Liu \& Lustig 1996; Luo et al. 2002; Moretti \& Shore 2001; Moretti et al. 1994).

S. cerevisiae Rap1 has a central myb domain that is quite similar to the classical myb DNA binding motif, with the three helices forming a helix-turn-helix structure (Fig. 2) (Konig et al. 1996). In addition, ScRap1 also has a myb-like domain baring an atypical long insertion between its first and second helices (Konig et al. 1996). Nevertheless, the myb and myb-like domains are able to coordinate with each other and enable ScRap1 to bind the duplex telomere DNA directly (Konig et al. 1996). It is interesting to note that human RAP1 appears to contain only one myb domain ( $\mathrm{Li}$ et al. 2000), whose third helix presents a negatively charged surface (Hanaoka et al. 2001), so it does not interact with telomere DNA directly. Rather, human RAP1 is tethered to the telomeres through its interaction with TRF2, a duplex telomere DNA binding factor. Similarly, S. pombe Rap1 seems to rely on SpTaz1, the duplex telomere DNA binding factor in S. pombe and a TRF homolog (Cooper et al. 1997; Li et al. 2000), to recruit it to the telomere. In support of this, SpRap1 is rarely found to localized at the telomere in SpTaz1 null cells (Cooper et al. 1997; Kanoh \& Ishikawa 2001). However, it is not clear whether residue amount of SpRap1 may still be associated with the telomere independent of SpTaz1. The RAP1 homolog has also been identified in Trypanosoma brucei, a protozoan parasite, and it seems to have both the myb and myb-like domains (Yang et al. 2009). Preliminary structural analysis of the myb-like domain suggests that TbRAP1 may have some weak sequence non-specific DNA binding activities (Zhao Y. $\& \mathrm{Li}, \mathrm{B}$. unpublished data), but more careful analyses are necessary before a clear conclusion can be drawn.

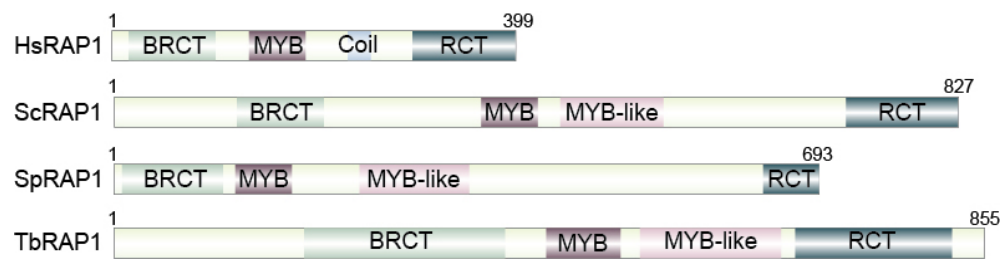

Fig. 2. Domain structure of RAP1 homologs. All RAP1s have a BRCT, a myb, and an RCT domain. In addition, except human RAP1, which has a Coil domain, all other RAP1 homologs have a myb-like domain next to the myb domain.

Other than the myb domain, RAP1 homologs have an N-terminal BRCA1 C Terminus (BRCT) domain at the N-terminal half of the protein (Bork et al. 1997; Callebaut \& Mornon 1997; Li et al. 2000; Yang et al. 2009), which is usually found in proteins involved in DNA damage response or cell cycle checkpoint and is often capable of binding proteins with phosphorylated peptide (Bork et al. 1997; Callebaut \& Mornon 1997; Glover et al. 2004). However, the function of BRCT domain in RAP1 homologs is still unknown. The very Cterminal region of RAP1 homologs is also conserved and termed RAP1 C-terminus (RCT) domain, which appears to be a protein-interacting domain, too (Li et al. 2000). Human RAP1 has an additional coiled-coil domain next to the myb domain, which may also have a protein-protein interaction function ( $\mathrm{Li}$ et al. 2000; O'Connor et al. 2004). Therefore, one 
striking feature of RAP1 is that it has several protein interacting domains, suggesting that this protein has a "recruiter" function that tethers various proteins to telomeres.

In addition to ScRap1, the yKu70/80 dimer is another factor that can recruit silencing factors to the telomere in the budding yeast (Boulton \& Jackson 1998; Laroche et al. 1998; Tsukamoto et al. 1997). Ku70/80 is a heterodimer complex that binds DNA ends in a sequence-independent manner (Riha et al. 2006). They were originally identified in mammalian V(D)J recombination process and play an essential function in the classical NHEJ pathway (Critchlow \& Jackson 1998; Weaver et al. 1995). The function of Ku homolog at telomeres varies in different organisms, and deletion of $\mathrm{yKu}$ leads to multiple defects including heat sensitivity, shortened telomere length, longer telomere G-overhang, abolished TPE, and mislocalization of ScRap1 in nucleus (Boulton \& Jackson 1996, 1998; Driller et al. 2000; Smith et al. 2008).

Recruitment of Sir2, Sir3, and Sir4 to telomeres is essential for establishment of the heterochromatic structure at the subtelomeric regions and TPE (Aparicio et al. 1991). Unlike Sir2 and Sir3, Sir4 remains telomere-bound when other Sir proteins are absent (Bourns et al. 1998; Luo et al. 2002), and Sir2/4 binds to chromatin independently of deacetylation at H4K16 and loss of Sir3 interaction in an in vitro analysis (Johnson et al. 2009), suggesting that Sir4 is the first one to be recruited to the telomere to initiate the silencing. Either ScRap1 or yKu can recruit Sir4 to the telomere, and ScRap1 can also recruit Sir3 (Luo et al. 2002; Martin et al. 1999; Moretti \& Shore 2001; Moretti et al. 1994; Tsukamoto et al. 1997). Together, Sir3 and Sir4 can recruit Sir2 (Bourns et al. 1998; Buchberger et al. 2008; Martino et al. 2009; Moazed et al. 1997; Strahl-Bolsinger et al. 1997), which is an NAD ${ }^{+}$-dependent histone deacetylase (Landry et al. 2000; Smith et al. 2000; Tanny et al. 1999). Sir2 activity and the interaction between Sir3/4 and histone tails are necessary for propagating of the heterochromatic structure from telomere to chromosome internal regions (Hoppe et al. 2002).

Sir2 can remove the acetyl group from histone $\mathrm{H} 3$ at $\mathrm{K} 9$ and $\mathrm{K} 14$ residues and from histone H4K16 (Imai et al. 2000). Particularly, unacetylated H4K16 can be recognized by Sir3 (Hecht et al. 1995). Binding of Sir3 on H4K16 will block Dot1 (Altaf et al. 2007), which specifically methylates histone H3K79 (Feng et al. 2002; Lacoste et al. 2002; Ng et al. 2002; van Leeuwen et al. 2002). As an antagonizing effect, methylation of H3K79 by Dot1 will prevent Sir3 from binding the nucleosome (Ng et al. 2002). Similarly, Set1 and Set2 methylates H3 on K4 and K36 residues, respectively (Krogan et al. 2002; Nagy et al. 2002; Roguev et al. 2001; Strahl et al. 2002), and methylated histone H3 prevents Sir4 from binding the nucleosome (Tompa \& Madhani 2007; Venkatasubrahmanyam et al. 2007). Therefore, binding of Sir3 and Sir4 recruits Sir2, which deacetylates neighboring histone tails and allows subsequent binding of Sir3 and Sir4 to neighboring nucleosome. Repetitive Sir3 and Sir4 binding and Sir2 action effectively propagate the heterochromatin structure (Rusche et al. 2002). Finally, Sir2 activity can be counteracted by Sas2-dependent acetylation of H4K16 (Ehrenhofer-Murray et al. 1997; Kimura et al. 2002; Reifsnyder et al. 1996; Suka et al. 2002). In fact, a gradient of acetylated H4K16 has been observed where internal chromosomal regions are hyperacetylated while telomeric regions are hypoacetylated, which also corresponds to an inverse gradient of Sir3 binding to chromatin (Kimura et al. 2002).

TPE in S. cerevisiae appears to depend on the length of the telomere tract: the longer the telomere, the stronger the silencing effect (Eugster et al. 2006; Kyrion et al. 1993; Renauld et 
al. 1993). Presumably, longer telomeres are bound by more ScRap1 proteins, which in turn recruit more Sir proteins to the telomere and lead to stronger silencing.

In $S$. cerevisiae, TPE levels at different telomeres vary dramatically, particularly at native telomeres (Loney et al. 2009; Pryde \& Louis 1999). This is largely because different telomeres have different composition of subtelomeric elements (Zakian \& Blanton 1988). S. cerevisiae has two subtelomeric elements, $X$ (contains a core $X$ element) and $Y^{\prime}$ (Fig. 3) (Louis 1995; Zakian \& Blanton 1988). The $X$ element is present at all yeast telomeres, and core $X$ has an ARS consensus sequence (ACS) that is bound by the ORC complex (which is the DNA replication origin recognition complex) and an ABF1 binding site (Diffley \& Stillman 1989; Foss et al. 1993; Marahrens \& Stillman 1992; Micklem et al. 1993; Rao et al. 1994; Wyrick et al. 2001). The core $X$ element can reinforce silencing when located near a master silencer such as the telomere, but itself does not convey any silencing effect (Lieb et al. 2001). Therefore, core $\mathrm{X}$ is considered as a protosilencer (Boscheron et al. 1996; Lebrun et al. 2001). The X-ACS (ORC binding site) and the ABF1 binding sites of the core $\mathrm{X}$ both contribute to silencing at XI-L telomere (Diffley \& Stillman 1989; Wyrick et al. 1999). In addition, Sir1, which is not required for TPE at the truncated telomeres (Aparicio et al. 1991), participates in silencing at XI-L telomere (Fourel et al. 1999; Pryde \& Louis 1999), presumably by interaction with ORC (Triolo \& Sternglanz 1996). The $Y^{\prime}$ element is not ubiquitous at all yeast telomere. Only 50$70 \%$ of telomeres are marked with 1-4 copies of subtelomeric $Y^{\prime}$ elements, which always reside between the $X$ element and the telomere (Chan \& Tye 1983a, b; Zakian \& Blanton 1988) (Fig. 3). $Y^{\prime}$ has two open reading frames (ORF), an ARS, and a SubTelomeric Antisilencing Region (STAR) element adjacent the telomere repeats. Within the $X$ and $Y^{\prime}$ elements, there is a small domain of repression centering on the X-ACS, but limited repression is observed through out the $Y^{\prime}$ (Pryde \& Louis 1999). Therefore, TPE at X-only telomeres is usually stronger.

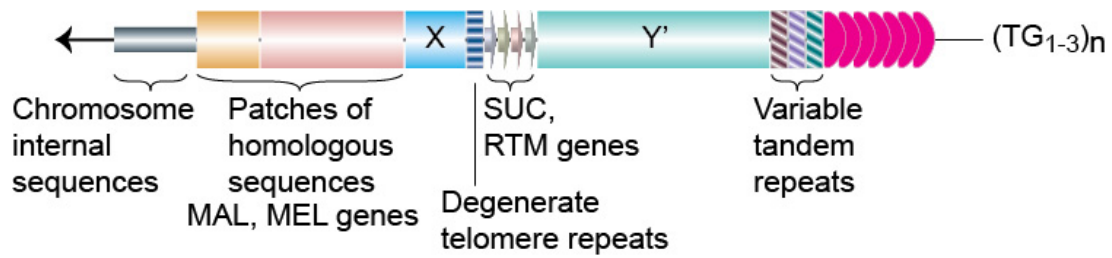

Fig. 3. The subtelomere elements in S. cerevisiae. The telomere-proximal region of S. cerevisiae subtelomere contains a ubiquitous Core $X$ element and 0-4 copies of $Y^{\prime}$ elements.

Degenerated telomere repeats and SUC/RTM gene families separates the $\mathrm{X}$ and $\mathrm{Y}^{\prime}$ elements, while variable tandem repeats separate the $Y^{\prime}$ and the telomere $\mathrm{TG}_{1-3}$ repeats. The telomeredistal part of yeast subtelomere consist of $M A L$ and $M E L$ gene families as large patches of homologous sequences.

At truncated telomeres with targeted reporter genes, TPE levels decrease exponentially with increased distance to the telomere, and the silencing effect spreads inward continuously (Gottschling et al. 1990; Renauld et al. 1993). This is not always true at the native telomeres. Regions closer to telomeres may not be affected by TPE because of the STAR boundaries, while regions more distal to telomeres may resume TPE because of nearby protosilencers such as the core X (Pryde \& Louis 1999). Therefore, TPE may not spread continuously along a native telomere. 
In S. cerevisiae, telomeres are clustered into several foci and are mainly located at the periphery of the nucleus (Gotta et al. 1996). Esc1 is a protein that localizes at the nuclear periphery and plays an important role in the association of telomeres with nuclear envelope (Taddei \& Gasser 2004). First, Esc1 interacts with the PAD4-domain of Sir4. Second, Esc1 can also interact with $\mathrm{yKu}$ in the $\mathrm{S}$ phase, which contributes to the periphery localization of telomeres independently (Taddei \& Gasser 2004). Although nuclear periphery localization is not strictly required for TPE (Gartenberg et al. 2004), artificial tethering a reporter gene flanked by silencers to nuclear periphery facilitates the silencing (Andrulis et al. 1998). It is therefore hypothesized that the telomere-clustering site might be a subnuclear compartment that is concentrated with silencing factors such as Sir proteins.

\subsection{TPE in S. pombe}

Silencing has been observed at pericentromeric loci, mating type loci, and telomeres/subtelomeres in S. pombe (Grewal \& Jia 2007). These loci all have the same signature heterochromatic structure - methylated H3K9 that is bound by Swi6 (HP1 homolog) (Ekwall et al. 1995; Nakayama et al. 2001). Methylation of H3K9 by Clr4 and subsequent Swi6 binding at pericentric and mating type loci are mediated by RNAi-RITS complex (Cam et al. 2005; Hall et al. 2002; Noma et al. 2004; Petrie et al. 2005; Sadaie et al. 2004; Volpe et al. 2002). For a comprehensive review about the RNAi-mediated gene silencing in S. pombe, please refer to (Creamer \& Partridge 2011). TPE in S. pombe is mediated through at least two independent pathways: an SpTaz1-dependent and an RNAi RITSdependent pathway (Kanoh et al. 2005; Park et al. 2002; Sugioka-Sugiyama \& Sugiyama 2011). The SpTaz1-dependent pathway relies on the telomere repeat DNA. SpTaz1, SpRap1, SpPoz1, SpTpz1, SpCcq1, and SpPot1 interact one with another and form the core telomere protein complex at the $S$. pombe telomere (Dehe \& Cooper 2010). SpCcq1 also interacts with SHREC, which promotes the Clr4-dependent methylation of H4K9 (Sugiyama et al. 2007). As a separate mechanism, a cenH-like sequence is found at the subtelomeric regions of $S$. pombe telomeres, which is used by RNAi-RITS pathway for establishment of Swi6 heterochromatin (Kanoh et al. 2005). Therefore, TPE depends on not only the telomere sequence but also subtelomeric elements in S. pombe.

\subsection{TPE in D. melanogaster}

D. melanogaster is the first organism in which TPE was observed (Gehring et al. 1984; Hazelrigg et al. 1984; Levis et al. 1985), and its telomere consists of reverse transposon elements instead of the simple repetitive TG-rich sequences (Pardue \& DeBaryshe 2008), which is very different from most other eukaryotes (see Chapter 5). At the very end of the reverse transposon arrays (including HeT-A, TART, and TAHRE, or the HTT array (Abad et al. 2004; Biessmann et al. 1992; Levis et al. 1993)) lies the cap, which is bound by sequencenonspecific proteins such as HP1 and HOAP to protect the very end of the chromosome independent of HTT array (Cenci et al. 2003; Fanti et al. 1998). At regions immediately internal to the HTT array lie the telomere-associated sequences (TAS), which contain several kilobases of complex satellite repetitive DNA sequences (Karpen \& Spradling 1992; Walter et al. 1995).

Not only is D. melanogaster telomere sequence unusual, but also has TPE in D. melanogaster some unique features. First, TAS, rather than HTT array, is the telomere silencer (Biessmann 
et al. 2005). Reporter genes targeted inside TAS or in HTT close to TAS are repressed, while those targeted inside HTT array but more than $5 \mathrm{~kb}$ away from TAS are not (Boivin et al. 2003). This may be partly because the transposon elements contain transcribed ORFs (Biessmann et al. 1994). Second, although usually both methylated H3K9 and methylated H3K27 are markers for inactive chromatin, methylated H3K9 is found at HTT but not at TAS while methylated H3K27 is absent from HTT but present at TAS and the cap (Andreyeva et al. 2005). E(Z) is a histone methyltransferase that modifies H3K27, and it is also found to be enriched at TAS. However, although HP1 usually binds methylated H3K9, it does not associate with the HTT array (Frydrychova et al. 2008). Furthermore, silencing level depends on TAS array length and orientation (Mason et al. 2003), but the spreading of silencing varies among different telomeres, possibly because of different HTT and TAS composition at various telomeres (Cryderman et al. 1999; Wallrath \& Elgin 1995).

\subsection{TPE in mammalian cells}

TPE has been observed in human and mouse cells (Baur et al. 2001; Koering et al. 2002; Pedram et al. 2006). By transfecting a linear plasmid carrying a selective marker and a luciferase gene adjacent to a $1.6 \mathrm{~kb}$ telomere repeat seed into the telomerase positive Hela cells, a new telomere was formed next to the markers, and the luciferase gene was expressed at a level on average ten-fold lower than when it is at non-telomeric sites. Human TPE is similar to that in yeast - it is variegated and spreads from the telomere inwardly. The silencing strength is also dependent on the length of the telomere, although there is no simple correlation between telomere length and TPE level in both human and yeast (Baur et al. 2001; Koering et al. 2002). TPE in human cells appears to be mediated by the heterochromatic chromatin structure, as treatment with Trichostatin A, an inhibitor of class I and II histone deacetylases, led to decreased TPE. Normally, all three HP1 paralogs associate with telomeres (Koering et al. 2002). However, after Trichostatin A treatment, both histone H3 methylation and the amount of telomere-associated HP1 decrease (Koering et al. 2002). Human subtelomeric elements are much more complicated than that in yeast (Fig. 4). Although some studies suggested that certain subtelomeric elements are important for telomeric silencing, no consistent observations have been made.

\section{Telomere and subtelomere recombination}

As mentioned above, telomere recombination can serve as an important means for telomere maintenance when telomerase is absent in yeast and mammalian cells (McEachern \& Haber 2006; Nabetani \& Ishikawa 2011). in addition, telomere recombination can participate in telomere length regulation in telomerease positive cells, too. In S. cerevisiae, abnormally long telomeres are observed to shorten in an apparently single-step process called telomere rapid deletion (TRD) (Li \& Lustig 1996). TRD depends on RAD52, indicating that DNA recombination is involved. Further analysis showed that it is an intrachromatid telomere recombination event and depends on telomere clustering. However, telomere recombination appears to be a low frequent event in wild-type cells. As discussed above, in mammalian cells, sister telomere exchanges and extrachromosomal telomere circles resulted from introchromatid telomere recombination are rarely observed in non-ALT cells (LondonoVallejo et al. 2004), which is presumably because telomere recombination events are normally inhibited by telomere specific proteins: Both the N-terminus deletion mutant of 
TRF2 and depletion of RAP1 led to an elevated telomere sister chromatid exchanges when analyzed by CO-FISH, and the N-terminus deletion mutation of TRF2 also led to an increased extrachromosomal telomere circles presumably as a result of elevated intrachromatid telomere recombination (Martinez et al. 2010; Sfeir et al. 2010; Wang et al. 2004).

Subtelomeric repeats are the sequences located next to telomeres. They are defined as patchworks of blocks that are duplicated near the ends of multiple chromosomes and are highly dynamic with very heterogeneous sequences, sizes, and copy numbers (Mefford \& Trask 2002). However, similar organization of subtelomere elements have been observed in organisms that are distantly related such as Homo sapiens, S. cerevisiae, and Plasmodium falciparum.

Although a detailed sequence database is still lacking for human subtelomere elements on all chromosome ends, recent studies have revealed a common structure (Fig. 4): a proximal and a distal subtelomeric domain is separated by a stretch of degenerate TTAGGG repeats (Mefford \& Trask 2002). The telomere-proximal (closer to telomere) domain usually contains short repetitive sequences that can be found at many chromosome ends, while the telomeredistal (more chromosome internal) domain usually consist of longer blocks of homologous sequences that are only found at a few chromosome ends (Brown et al. 1990; Cross et al. 1990; de Lange et al. 1990; Ijdo et al. 1992; Wilkie et al. 1991). In addition, genes belonging to the olfactory receptor family have been found in subtelomeric region (Trask et al. 1998). Olfactory receptor is a membrane-spanning receptor in the sensory neuroepithelium of the nose that bind volatile odorants. Upon binding the ligand, the receptor initiates a signaling cascade that results in transmission of an electrical signal to the brain (DeMaria \& Ngai 2010). In any olfactory receptor cell, only one type of olfactory receptor is expressed (Serizawa et al. 2004; Shykind 2005), which is not unlike the monoallelic expression of surface antigen genes in several microbial pathogens (see below).

The subtelomeres of $S$. cerevisiae also consist of two domains that are separated by the Core $X$ element (Fig. 3) and often a stretch of degenerate telomere repeats (Louis 1995). The Core $X$ element is present at all telomeres with a 57-92\% of sequence identity across different chromosomes (Louis \& Haber 1991; Louis et al. 1994). The telomere-proximal domain consist of 0-4 repeats of $Y^{\prime}$ elements, which are highly conserved (98-99\% sequence identity) across all chromosomes (Louis \& Haber 1992). The telomere-distal domain contains sequence blocks that are only homologous to a few subtelomeres and includes gene families that function in the use of different carbon sources such as MAL ( $\alpha$-glucosidase/maltose permease) and MEL ( $\alpha$-glactosidase) (Carlson \& Botstein 1983; Carlson et al. 1985; Charron \& Michels 1988; Charron et al. 1989; Louis \& Haber 1992; Naumov et al. 1992; Ness \& Aigle 1995; Turakainen et al. 1993; Viswanathan et al. 1994).

In Plasmodium falciparum that causes malaria in humans, subtelomeres are also arranged into two major domains (Fig. 5A) (Scherf et al. 2001): The telomere-proximal domain consists of six Telomere-Associated Repetitive Elements (TAREs), which are variable tandem repeats (De Bruin et al. 1994; Figueiredo et al. 2002; Pizzi \& Frontali 2001), and a couple of these elements are transcribed as long non-coding RNA (Broadbent et al. 2011). The telomeredistal domain consists of a number of gene families including rif and var genes that encode virulence factors expressed at the surface of the infected host cells and involved in antigenic variation (see below) (Cheng et al. 1998; Rubio et al. 1996). 


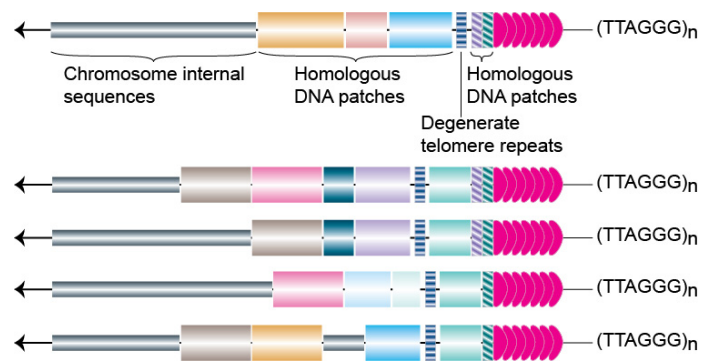

Fig. 4. The organization of subtelomere elements on human chromosomes. The telomereproximal region usually consists of short patches of homologous DNA sequences that are common at multiple chromosome ends. The telomere-distal region, on the other hand, consists of longer patches of homologous DNA sequences, and degenerated telomere repeats separate the distal and proximal regions.

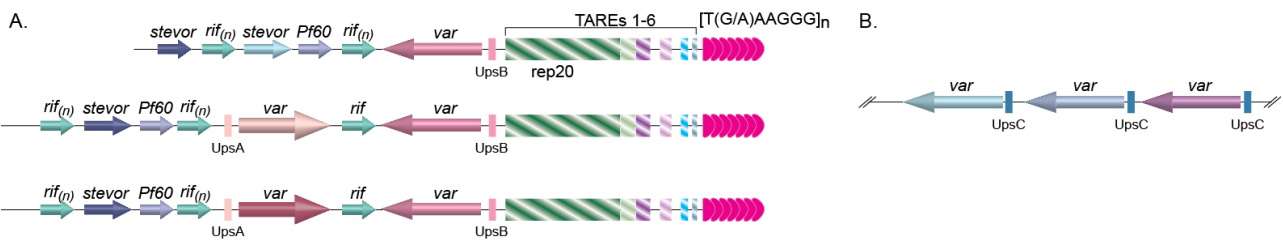

Fig. 5. (A) The organization of subtelomere elements in P. falciparum. Immediately internal to the telomere tract are six Telomere-Associated Repeat Elements (TAREs 1-6), with the largest one, rep20, located furthest away from the telomere repeats. One or two var genes are usually found immediately upstream of rep20, followed by the rifin, stevor, and Pf60 gene families. Depending on the upstream flanking sequences, three classes of var genes have been identified. The ones with associated UpsB and UpsA are located at subtelomeric regions and transcribed in opposite directions as drawn, while the ones with associated $\mathrm{UpsC}$ are located as gene arrays in chromosome-internal loci (B).

Subtelomere sequences from many organisms appear to have been duplicated and dispersed among many chromosome ends. It has been hypothesized that translocation recombination events may lead to swapping of chromosome ends, gene conversion events may lead to replacement of all or part of a subtelomeric region by another, and transposition-like events may lead to duplications (Mefford \& Trask 2002). In addition, many of these events appear to occur recently because subtelomeric content of a given chromosome varies markedly among individuals. In human cells, FISH analysis revealed high degree of recent genomic rearrangement in human subtelomeres, and sequencing analysis showed that for the two homologous alleles of $16 \mathrm{p}$, sequence identity decreases from $99.8 \%$ at unique chromosomal sequence region to $93 \%$ at subtelomeric region (Linardopoulou et al. 2005). These studies suggested a two-step event contributed to subtelomere organization: initial interchromosomal translocation events predominantly mediated by NHEJ created new blocks of homologous sequences, and subsequent mutations or homology-directed sequence transfers further enhance sequence variations and spread the subtelomeric elements to other chromosomes (Linardopoulou et al. 2005). The human subtelomere regions therefore exchange sequences at a remarkably high rate and represent recombination hot spots. In S. cerevisiae, although subtelomeres are poor substrates for 
meiotic recombination because chiasmata formed near the ends of chromosomes are much less efficient at promoting homologous chromosome segregation (Su et al. 2000), a high level of nucleotide divergence among Sacharomyces yeasts has been observed at the subtelomeres (Teytelman et al. 2008). In S. pombe, mutations disrupting heterochromatin led to elevated subtelomeric duplication and rearrangements that are RAD50-dependent, indicating that subtelomeres are susceptible to high rate of homologous recombination but the heterochromatic telomere structure can help suppress these events (Bisht et al. 2008).

The subtelomere elements do not seem to have any essential functions (Corcoran et al. 1988; Murray \& Szostak 1983; Pologe \& Ravetch 1988; Thompson et al. 1997), but they can be useful in more than one way. Recombination at subtelomere regions can contribute to telomere maintenance (McEachern \& Haber 2006; Nabetani \& Ishikawa 2011). As described above, in telomerase negative $S$. cerevisiae cells, Type I survivors amplify subtelomeric elements using a RAD51-dependent mechanism (Le et al. 1999; Teng \& Zakian 1999). In addition, subtelomeric DNA recombination appears to be a major factor for genome plasticity, which may help to diversify the sequences of subtelomeric genes (Corcoran et al. 1988; De Bruin et al. 1994; Louis 1995; Pologe \& Ravetch 1988; Trask et al. 1998). Particularly for several microbial pathogens, subtelomere recombination appears to play important roles in antigenic variations (see below).

\section{Telomere functions in regulation of microbial pathogen virulence}

\subsection{Antigenic variation and phenotypic switch in microbial pathogens}

Living organisms, either unicellular or multicellular, have evolved sophisticated ways to adjust to their living environment for a better survival. Many microbial pathogens that infect mammals have adopted antigenic variation to avoid eradication by the host immune system so that they can maintain persistent infections and enhance the chances of being transmitted to new hosts (Deitsch et al. 2009).

Antigenic variation is the phenomenon that a pathogen changes its surface antigen presented to the host immune system regularly and much more frequently than spontaneous gene mutation. The term of antigenic variation usually encompasses both phase variation (the expression of an individual antigen switches between "on" or "off" states) and true antigenic variation (the expression of a certain antigen switches among different forms). In the latter case, the antigen is usually expressed in a mutually exclusive manner - a single gene from a multi-copy gene family is expressed at any time. In addition, many microbial pathogens can go through phenotypic switching in response to environmental conditions - change of gene expression patterns that leads to a change in organismal phenotypes, which, in turn, can also contribute to the virulence of the pathogen. For example, expression of a different type of certain surface molecule may enhance or weaken adhesion of the pathogen to the host and therefore affect the virulence of the pathogen. In general, both antigenic variation and phenotypic switching can occur through two general types of mechanisms: genetic and epigenetic (Deitsch et al. 2009). A genetic event involves changes in DNA sequences of an antigen encoding gene or its regulatory elements so that either its expression level or its gene product is changed. An epigenetic event only affects a gene expression level but does not change its DNA sequences. However, recent studies suggest that epigenetic changes such as chromatin remodeling may also influence genetic events such as DNA recombination (Benetti et al. 2007; Bisht et al. 2008). 
Antigenic variation occurs widely among various microbial pathogens including virus, bacteria, fungi, and parasites (Deitsch et al. 2009). Common mechanisms of antigenic variation have been evolved in different pathogens, including bacteria, fungi, and parasites, possibly due to similar selection pressure exerted from the mammalian immune responses. However, in this chapter, we will focus on those mechanisms that are influenced by the telomere structure.

\subsection{TPE participates in the regulation of EPA expression in C. glabrata}

Candida glabrata is part of the normal human mucosal flora and usually commensal. It is a prevalent yeast pathogen, ranking only second to Candida albicans, and like C. albicans, it can cause opportunistic mucosal and bloodstream infections in immunocompromised individuals. During infection, binding of the pathogen to host cells, host cell proteins, or microbial competitors would help to reduce the chance of clearance by the host. Therefore, the adherence of C. glabrata to host cells has been proposed to play an important role in its virulence (Kaur et al. 2005).

When cultured human epithelial cells are used, $95 \%$ of in vitro C. glabrata adherence depends on an adhesin molecule encoded by the EPA1 gene (Kapteyn et al. 1999), which binds the host N-acetyl lactosamine-containing glycoconjugates (Castano et al. 2005). The EPA1 gene belongs to the EPA gene family. So far, a total of 23 putative EPA genes and pseudogenes have been identified in C. glabrata strain BG2 based on their sequence similarity (Kaur et al. 2005). Seven EPA genes encode full-length GPI-anchored proteins, among which Epa1 is a lectin (Cormack et al. 1999), Epa6 and Epa7 are confirmed to be adhesins (Castano et al. 2005), while Epa2 and Epa3 are predicted to be cell wall proteins (De Las Penas et al. 2003). All seven EPA genes located at subtelomeric regions (Fig. 6) (Castano et al. 2005; De Las Penas et al. 2003; Iraqui et al. 2005). EPA1, EPA2 and EPA3 are at the same subtelomere, and EPA1 is the furthest from the telomere (De Las Penas et al. 2003). EPA4 and EPA5 are located on a different subtelomere as near-perfect inverted repeats (De Las Penas et al. 2003). EPA6 and EPA7 are located on yet two other subelomeres, both are only $\sim 2.5 \mathrm{~kb}$ from the telomere tracts (Castano et al. 2005).

Normally, only EPA1 gene is active, while EPA2-7 genes are silenced by TPE (Castano et al. 2005; De Las Penas et al. 2003). Like S. cerevisiae, TPE in C. glabrata dependents on telomere DNA binding factor Rap1. Deletion of the C-terminal 28 amino acids of Rap1 led to derepression of EPA4-7 and in another case, also EPA2 and EPA3 (De Las Penas et al. 2003). This rap1 allele is equivalent to rap1-21 mutant allele in S. cerevisiae (Liu \& Lustig 1996), which causes similar loss of TPE phenotype. Silencing of subtelomeric EPA genes also depends on Sir proteins (Castano et al. 2005; De Las Penas et al. 2003). Deletion of SIR3 led to hyper expression of EPA1 and derepression of EPA2-7, although the derepression of $E P A 2$ and EPA3 is very mild, and derepression of EPA4/5 is also not as strong as that of EPA6 and EPA7. Deletion of SIR4 also led to derepression of EPA6. In addition, deletion of RIF1 led to elongated telomeres and dererepssion of EPA4-7, but not EPA2 or EPA3 (Castano et al. 2005). The different derepression of different EPA genes indicated that TPE at different telomeres varies, which is the same as in $S$. cerevisiae at native telomeres. In the case of deletion of SIR3 or RIF1, expression of EPA6 and EPA7 appears to be the reason or at least one of the reasons for hyper-adherent phenotype, demonstrating that TPE can be directly involved in regulation of pathogen virulence (Castano et al. 2005). Interestingly, Epa6 
expression is associated with the ability of $C$. glabrata cells to form biofilm on plastic surface (Iraqui et al. 2005). Biofilm formed by microbial pathogens can increase infection probability and is of great clinical importance because microorganisms adopting this life form is more tolerant or resistant to host defense machinery and anti-microbial agents than free cells.

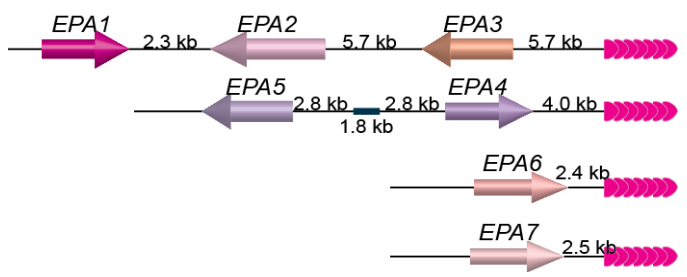

Fig. 6. EPA1-7 are located at subtelomeric loci in C. glabrata. The positions of seven EPA genes at their respective chromosome end loci are shown. EPA1 is furthest away from the telomere and is the only one that is expressed normally, while EPA 2-7 are usually silenced by TPE.

This TPE regulated adhesin gene expression is well exploited by C. glabrata to sense a particular host environment. C. glabrata is an nicotinic acid (NA or vitamin niacin) auxotroph, as it lost all the BNA genes involved in the NA synthesis except BNA5 (Domergue et al. 2005). When growing in urine, where NA is limited, the activity of Sir2, an $\mathrm{NAD}^{+}$-dependent histone deacetylase, decreases correspondingly since NA is the precursor of $\mathrm{NAD}^{+}$. As a consequence, TPE level decreases and EPA1, 6, and 7 genes are highly expressed (Domergue et al. 2005). This effect can be reverted by adding NA or a related compound nicotinamide (NAM). Most importantly, when using an established murine model of urinary track infection, transurethrally inoculated C. glabrata has an elevated colonization frequency in bladder and kidney, which is dependent on EPA1, 6 and 7 gene expression, and mice fed with high-NA diet are no longer susceptible for high rate of colonization of C. glabrata (Domergue et al. 2005). Therefore, in C. glabrata, TPE plays an important role in regulation of expression of virulence genes.

A similar regulatory role of TPE has also been observed in S. cerevisiae, which is not a human pathogen. In S. cerevisiae, 5 flocculin genes of the FLO family encode cell-wall glycoproteins that regulate cell-cell and cell-surface adhesion, which are important for cell flocculation (Reynolds \& Fink 2001; Van Mulders et al. 2009). In this family, FLO11 is located at a nontelomeric locus and is usually expressed, while FLO1, 5, 9, and 10 are at subtelomeric regions (10-40 kb from the telomere repeats) and are normally silenced (Halme et al. 2004). Silencing of FLO10 requires Sir3 and yKu, suggesting that FLO gene silencing and TPE share some common mechanisms. However, silencing of FLO10 does not require Sir2 and is promoter dependent, indicating that this silencing is not identical to TPE.

\subsection{Sir2-mediated TPE plays an essential role in manoallelic expression of var genes in $P$. falciparum}

Plasmodium falciparum is a protozoan parasite in the Apicomplexa phylum that causes the most severe form of malaria, which is a debilitating and sometimes fatal disease mostly found in tropical and subtropical regions of the world and is most common in Africa. After P. falciparum cells being injected into a mammalian host by a female Anopheline mosquito, 
the sporozoites first invade hepatocytes. At this liver stage, parasites undergo asexual multiplication and differentiate into merozoites, which eventually burst from the hepatocyte and invade erythrocytes (red blood cells). While inside the erythrocytes, individual merozoite enlarges and differentiates into mononucleated ring trophozoites. The trophozoite's nucleus then divides asexually to produce a schizont with several nuclei. Subsequently, schizont divides and produces more mononucleated merozoites. When the erythrocyte erupts eventually, more merozoites and toxins are released to the host bloodstream. The released merozoites will infect more erythrocytes, and the synchronous rupture of the infected erythrocytes is the reason for the periodical fever and chills, typical symptoms of malaria. Some merozoites differentiate into sexual gametocytes inside the erythrocytes. These can be taken up by another mosquito and sexual reproduction is completed inside the insect intestine wall, after which, sporozoites are formed and migrated to the salivary gland of the mosquito, ready to infect next mammalian host when the mosquito takes another blood meal.

One major reason why it is very difficult to eliminate Plasmodium parasites once an infection is established is that $P$. falciparum undergoes antigenic variation at the erythrocyte stage (Dzikowski \& Deitsch 2009). Merozoites produce P. falciparum erythrocyte membrane protein 1 (PfEMP1), which is encoded by var genes and is transported to the infected erythrocyte membrane (Baruch et al. 1995; Smith et al. 1995; Su et al. 1995). Expression of PfEMP1 on the infected cell surface allows the infected erythrocyte to adhere to the endothelium of the post-capillary venules and avoid circulation through the spleen, where the infected cells will be destroyed (Baruch 1999). Therefore, expression of PfEMP1 on host cell surface is critical for prolonged parasite infection. However, PfEMP1 is also susceptible to host antibody recognition and subsequent immune attack. As an important pathogenesis mechanism, $P$. falciparum regularly switches the expressed PfEMP1, therefore effectively evading the host immune attack (Roberts et al. 1992). Other proteins encoded by rif and stevor genes appear to be also important for P. falciparum virulence (Kaviratne et al. 2002; Khattab \& Meri 2011; Kyes et al. 1999), but var gene switching is by far the best understood.

There are $\sim 60$ var genes in the P. falciparum genome (Gardner et al. 2002). However, only one var gene is expressed at any moment (Roberts et al. 1992). Based on its upstream regulatory elements, var genes can be classified into three groups (Fig. 5) (Kraemer \& Smith 2003; Lavstsen et al. 2003). Those with UpsA and transcribed towards the telomere and those with UpsB and transcribed away from the telomere are located at subtelomeric loci (Fig. 5A), while the ones with UpsC are located at chromosome internal loci (Fig. 5B) (Gardner et al. 2002; Kraemer \& Smith 2003; Lavstsen et al. 2003; Voss et al. 2000). Monoallelic expression of var gene is regulated at the DNA level, affected by epigenetic factors such as the chromatin structure, and depends on its subnuclear localization (Dzikowski \& Deitsch 2009). Telomeres appear to be important in the latter two mechanisms.

All var genes contain a larger exon 1, an intron of $\sim 800 \mathrm{bp}$, a smaller exon 2, and two promoters (Calderwood et al. 2003; Su et al. 1995). The promoter located upstream of exon 1 drives the expression of the var gene, which is subject to mutually exclusive expression regulation and hence only one is active at any time, while the promoter located within the intron appears to be active in most if not all var genes (Epp et al. 2009). Studies have shown that proper silencing of the var gene relies on the intron promoter activity, the pairing of the upstream and intron promoters, and passing through at least one cell cycle (Calderwood et 
al. 2003; Deitsch et al. 2001; Dzikowski et al. 2007; Frank et al. 2006). The detailed mechanism underlying the regulatory role of the intron promoter is still unknown. However, it has been proposed that the sterile transcripts resulted from the intron promoter may contribute to var gene silencing in a similar way as how non-coding RNA is involved in chromatin-mediated silencing and the inactivation of genes (Ralph \& Scherf 2005).

Other studies have shown that epigenetic factors also contribute to var gene expression regulation. For example, acetylated histone $\mathrm{H} 3$ and methylated $\mathrm{H} 3 \mathrm{~K} 27$ are found at active var gene promoters, while tri-methylation of $\mathrm{H} 3 \mathrm{~K} 9$ is found at silent var gene promoters (Chookajorn et al. 2007; Duraisingh et al. 2005; Freitas-Junior et al. 2005; Lopez-Rubio et al. 2007). Particularly relevant to this chapter, TPE has been shown to play an important role in var gene expression regulation (Duraisingh et al. 2005; Freitas-Junior et al. 2005; Tonkin et al. 2009). TPE was first observed in P. falciparum by targeting a reporter gene to the rep20 repeats located at the subtelomeric regions (Fig. 5A) (Duraisingh et al. 2005). Rep20 is the most telomere-distal TARE and is usually adjacent to the subtelomeric var gene promoter. TPE in P. falciparum is similar to that in S. cerevisiae in that it depends on Sir2 (Duraisingh et al. 2005; Freitas-Junior et al. 2005; Tonkin et al. 2009). However, PfSir2 is both a histone deacetylase and an ADP-ribosyltransferase (Chakrabarty et al. 2008; Merrick \& Duraisingh 2007), and the Sir2-dependent TPE spreads much further away along the chromosome in $P$. falciparum $(\sim 55 \mathrm{~kb})$ than in $S$. cerevisiae $(\sim 3 \mathrm{~kb})$. PfSir2 is localized at the telomeres, and histones $\mathrm{H} 4$ acetylation is absent from the telomeres (Freitas-Junior et al. 2005). By examining subnuclear localization of a number of genetic markers along chromosome 2 in FISH, it is also inferred that chromatin structure is more condensed for telomere-proximal regions than telomere-distal ones (Freitas-Junior et al. 2005). The direct evidence of involving TPE in var gene regulation came from the observation that deletion of PfSir2 led to a significant increase in transcription of a subset of var genes, particularly the var genes with UpsA and at the subtelomere regions (Duraisingh et al. 2005).

Telomeres appear to be involved in another layer of var gene expression regulation - specific subnuclear localization (Dzikowski \& Deitsch 2009). Several studies showed that silent var genes and active var genes are located in different compartments of the nucleus (Ralph et al. 2005). Specifically for var2csa located at a subtelomeric locus, when it is silent, it is predominantly colocalized with telomere clusters $(84 \%)$ at the nuclear periphery. However, when var2csa is active, it moves to a different nuclear periphery location away from the telomere clusters (Mok et al. 2008; Salanti et al. 2003). It is therefore hypothesized that telomeres are generally clustered in a heterochromatic region of the nuclear periphery where silent var genes are also located. Upon activation, var genes will leave the heterochromatic region and move to a euchromatic region in the nuclear periphery, allowing transcription to occur (Ralph et al. 2005). However, contrary observations were made for episomal located var genes, which tend to co-localize with the telomere cluster when activated (Voss et al. 2006). In addition, chromosome internally located var genes appear to co-localize with the telomere clusters independently of their transcriptional status (Voss et al. 2006). Nevertheless, it is clear that active var gene is relocated to a specialized peri-nuclear compartment for its proper transcription. In addition, var genes located at subtelomeres or chromosome internal loci appear to be differently regulated regarding their subnuclear localization. Apparently, in addition to telomeres, other genome environment factors are involved in var gene expression regulation. 


\subsection{RAP1-mediated silencing is essential for monoallelic expression of VSG in $T$. brucei}

The kinetoplastids are a group of flagellated protozoa. Three members of kinetoplastids are of great clinical importance because they cause human diseases: Trypanosoma brucei causes human African trypanosomiasis or sleeping sickness, Trypanosoma cruzi causes South America trypanosomiasis or Chagas Disease, and several Leishmania species cause leishmaniasis. Of these three trypanosomatids (the kinetoplastid organisms that only have a single flagellum), only $T$. brucei undergoes antigenic variation, which is an important mechanism of its pathogenesis and one of its most interesting physiological aspects (Barry \& McCulloch 2001).

Trypanosoma brucei is transmitted between its mammalian hosts by its insect vector, tsetse (Glossina spp.). T. brucei has several different life forms through its life cycle (Matthews 2005). While inside the mid-gut of a tsetse fly, T. brucei cells are in the procyclic form (PF), which is a non-virulent proliferative stage. After T. brucei cells migrate into the salivary gland of the tsetse fly, they differentiate into the metacyclic form. At this stage, T. brucei cells stop proliferating and acquire virulence. When a tsetse fly takes a blood meal, T. brucei cells can be injected into a mammalian host. T. brucei cells stay in the bloodstream or extracellular spaces in its mammalian host, and they quickly differentiate into bloodstream form (BF). The slender bloodstream form is proliferative, while the stumpy bloodstream form is quiescent, non-proliferative. When a tsetse fly takes a blood meal from the infected mammalian host, stumpy bloodstream form $T$. brucei cells can quickly differentiate into the procyclic form, ending the life cycle. Throughout its life cycle, T. brucei cells are covered with surface glycoproteins. At the PF stage, several Procyclic Acidic Repetitive Proteins (PARPs, or procyclins) are expressed at its surface, while the metacyclic form and bloodstream form cells express variant surface glycoproteins (VSGs) as their surface glycoprotein (Mehlert et al. 1998).

Because T. brucei cells stay in extracellular spaces in its mammalian host, they are exposed to the host's immune system and are not only vulnerable to the innate immune response (inflammations, complements, etc.) but also constantly threatened by the adaptive immune responses (antibody, killer $\mathrm{T}$ cells, etc.). However, T. brucei has evolved a sophisticated antigenic variation mechanism and regularly switches its surface VSG coat, thus effectively evading the host's immune attack (Barry \& McCulloch 2001).

Antigenic variation in T. brucei has two essential aspects: switch to express a different VSG gene (VSG switching) and monoallelic expression of VSG. Although there are 1,500 VSG genes and pseudogenes in the T. brucei genome (Berriman et al. 2005), only one type of VSG is expressed at any time. After a new VSG gene is turned on, it is essential to turn off the previously active VSG so that the old surface antigen is no longer presented to the host immune system. In addition, expressing only one VSG gene at a time would allow the VSG gene pool to be used for a maximum period of time, enabling a persistent infection. Therefore, both VSG switching and monoallelic expression of VSG are critical for antigenic variation and have been the focus of intensive research for several decades.

T. brucei has many unusual intriguing physiological aspects. In addition to the fact that it undergoes antigenic variation (Barry \& McCulloch 2001), most of T. brucei genes are arranged in polycistronic transcription units (Johnson et al. 1987; Mottram et al. 1989), and 


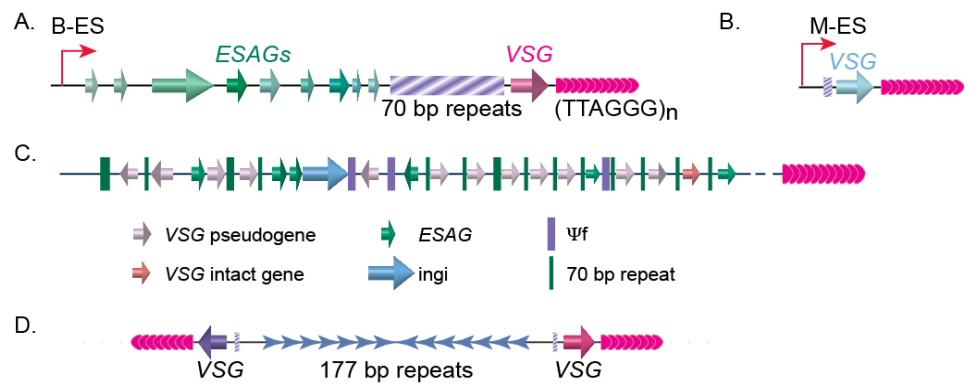

Fig. 7. Distribution of VSG genes in T. brucei genome. (A) In a bloodstream form VSG expression site (B-ES), the VSG gene is the last one in the large polycistronic transcription unit and is located within $2 \mathrm{~kb}$ from the telomere repeats. A stretch of $70 \mathrm{bp}$ repeats with various length is located upstream of the VSG gene followed by a number of ES associated genes (ESAGs). (B) The metacyclic VSG expression site (M-ES) is a monocyctronic transcription unit also located at subtelomeric region. (C) Most VSG genes (and some ESAG genes) are found in gene arrays located at subtelomeric regions on megabase chromosomes. Short stretches of $70 \mathrm{bp}$ repeats are found upstream of each gene. (D) On minichromosomes, single VSG genes and upstream 70 bp repeats are also found at subtelomeric regions.

the large polycistronic transcripts are trans-spliced so that each mature RNA molecule has a common 5' end spliced leader element (Liang et al. 2003). In BF T. brucei cells, VSGs are expressed exclusively from bloodstream form VSG expression sites (B-ESs), which are RNA polymerase I (RNAP I)-transcribed, polycistronic transcription units located at subtelomere loci (Fig. 7A) (de Lange \& Borst 1982; Gunzl et al. 2003). B-ESs usually consists of a number of Expression Sites-Associated Genes (ESAGs) upstream of the VSG gene, which is the last in the unit and usually within $1.5 \mathrm{~kb}$ from the telomere repeats, while the promoter is often 40 $60 \mathrm{~kb}$ upstream of the VSG (Hertz-Fowler et al. 2008). In contrast, at the metacyclic stage, VSGs are expressed from metacyclic VSG expression sites (M-ESs), which are monocistronic transcription units located at the subtelomeric regions (Fig. 7B), with the promoter located only $\sim 5 \mathrm{~kb}$ from the telomere (Cornelissen et al. 1985; Lenardo et al. 1984). Although the MESs have much simpler organizations than the B-ESs, much less is understood about metacyclic than bloodstream VSG expression regulation. T. brucei has multiple B-ESs (e.g. Lister 427 has 15 different B-ESs), usually carrying different VSGs, but all B-ESs have very similar genomic organization with $\sim 90 \%$ sequence identity (Hertz-Fowler et al. 2008). Earlier studies focused on B-ES promoters also showed that they are almost always identical (Pham et al. 1996; Zomerdijk et al. 1990, 1991). Therefore, how T. brucei manages to fully express only one B-ES and VSG had been a great puzzle for more than a couple of decades.

A number of studies in the last decade have shown that VSG expression is regulated at multiple levels. First, transcription elongation from B-ES promoter appears to be regulated. Silent B-ES promoters are actually mildly active (Vanhamme et al. 2000). Transcription is initiated from these "silent" promoters, but transcription elongation is quickly attenuated after a few kilobases, effectively stopping transcription long before the VSG genes. Second, chromatin structure is very different from the active to silent B-ESs. The active B-ES has very few nucleosomes while silent ESs are packed with nucleosomes (Figueiredo \& Cross 2010; Stanne \& Rudenko 2010). A number of studies also showed that chromatin remodeling 
plays an important role, particularly in regulating the B-ES promoter activity: Depletion of a Swi/Snf homolog, TbISWI, led to an elevated transcription from the silent ES promoters, although VSG expression is not affected (Hughes et al. 2007; Stanne et al. 2011); Deletion of the histone H3K79 methyltransferase TbDot1b led to a 10-fold increase in transcription throughout the silent ESs (Janzen et al. 2006); Of the three T. brucei histone deacetylase homologs, DAC3 is required for B-ES promoter silencing at both BF and PF stages, and DAC1 antagonizes basal telomeric silencing in BF cells without affecting B-ES transcription (Wang et al. 2010); And depletion of TbSpt16, a subunit of the FACT chromatin remodeling complex, also led to an $\sim 20$-fold increase in silent B-ES promoter transcription in both BF and PF cells (Denninger et al. 2010). Third, ever since the discovery that VSGs are exclusively expressed from subtelomeric regions (de Lange \& Borst 1982), it has been proposed that telomeres may play an important role in VSG expression regulation (Dreesen et al. 2007). This hypothesis was supported by the fact that T. brucei also has TPE (Glover \& Horn 2006; Horn \& Cross 1997). When a neo reporter gene driven by a B-ES promoter or an rDNA promoter (both are transcribed by RNAP I) is inserted into a silent B-ES, repression of the neo gene is observed to be stronger at loci immediately upstream or downstream the VSG gene than at loci 7 or $16 \mathrm{~kb}$ upstream of the telomere repeats (Horn \& Cross 1997). In a later study, the neo reporter gene with an rDNA promoter was integrated to a telomere not marked with any B-ES. Again, higher neo expression is detected at a locus $5 \mathrm{~kb}$ upstream of the telomere than at a locus only $2 \mathrm{~kb}$ from the telomere in both BF and PF cells, further confirming that TPE exist in T. brucei regulation (Glover \& Horn 2006). Interestingly, when the same reporter cassette is inserted in a silent B-ES at the same distance from the telomere as in a non-ES telomere, stronger silencing effect is detected in the silent B-ES, suggesting that in addition to TPE, other factors are involved in B-ES expression regulation (Glover \& Horn 2006).

Although the earlier studies provided promising evidence for TPE, direct evidence linking TPE and VSG silencing was lacking for a long time. In addition, although the T. brucei Sir2 homolog plays an essential role in TPE at reporter marked telomeres without native B-ESs, its deletion does not affect VSG silencing at all (Alsford et al. 2007). Furthermore, Glover et al. was able to target an I-Sce I digestion site together with a neo reporter gene downstream of the VSG gene and immediately upstream of the telomere in a telomerase null background. Induction of ectopic I-Sce I expression led to immediate cleavage and loss of the marked telomere. Within 9 hours, degradation of the reporter gene and the subtelomeric VSG gene was also observed. Although a mild derepression of the reporter gene was observed shortly before it was degraded, the VSG gene was not derepressed at all (Glover et al. 2007). These observations raised a great deal of doubts whether telomeres are indeed necessary for proper VSG silencing.

It was difficult to exam the roles of the telomere in antigenic variation directly without identifying any telomere specific proteins. Earlier attempts to identify telomere DNA binding factors in T. brucei using biochemical approaches led to the identification of a couple of telomere DNA binding activities without identification of the responsible proteins (Eid \& Sollner-Webb 1995, 1997).

Approximately nine years ago, the nearly completed T. brucei genome database allowed us to use an in silico approach to identify potential telomere protein homologs in T. brucei (Li et al. 2005). Because T. brucei telomere DNA consists of the same TTAGGG repeats as 
vertebrates, it was reasoned that the duplex telomere binding protein in T. brucei is likely to have a conserved functional domain for recognizing the double-stranded TTAGGG repeats as mammalian TRF homologs. Indeed, a T. brucei TRF homolog with a C-terminal conserved myb domain was identified in the genome database and was subsequently proved to bind the duplex TTAGGG repeats directly both in vitro and in vivo.

Although the initial study found that depletion of TbTRF does not affect VSG expression, a yeast 2-hybrid screen using TbTRF as bait led to the identification of T. brucei RAP1 homolog (Yang et al. 2009). Subsequent co-IP, immunofluorescence (IF), and Chromatin IP (ChIP) analyses further confirmed that TbRAP1 is an integral component of the T. brucei telomere complex. Extensive studies on S. cerevisiae Rap1 showed that it has a major function in establishment and maintenance of TPE (Kyrion et al. 1993; Liu et al. 1994). To determine whether TbRAP1 has a conserved function in TPE, we depleted TbRAP1 in BF cells using an RNAi approach (Shi et al. 2000), as TbRAP1 is essential for cell viability. As soon as the protein level of TbRAP1 started to decrease, a derepression of silent B-ES-linked VSGs can be detected (Yang et al. 2009). Using quantitative RT-PCR analysis, it was shown that all B-ES-linked silent VSGs had an elevated expression level upon depletion of TbRAP1, although the level of derepression varies among different VSGs, ranging from 8-56 fold. This is similar to situations in S. cerevisiae, where different levels of TPE are observed at different native telomeres (Pryde \& Louis 1999). Subsequently, it was confirmed by IF that multiple VSGs are expressed simultaneously in individual cells on cell surface (Yang et al. 2009). In addition, such VSG derepression effect is TbRAP1-specific, as depletion of TbTRF did not affect VSG silencing at all. Most importantly, the TbRAP1-mediated silencing is position dependent. First, only subtelomeric B-ES-linked VSGs were affected. Genes located in chromosome internal regions including RNAP I transcribed rDNA and RNAP II transcribed telomerase protein gene, a ribosomal protein gene, and a glycolytic protein gene were not affected. Second, along a same B-ES, the telomere-adjacent VSG gene is almost always derepressed at a higher level than a VSG pseudogene located 7-20 kb away from the telomere. The silencing effect spreads $40-60 \mathrm{~kb}$ away from the telomere and can cause derepression of a reporter gene targeted immediately downstream of the B-ES promoter. It is therefore convinced that the TbRAP1-mediated silencing originates from the telomere, demonstrating for the first time that the telomere structure indeed plays an essential role in VSG expression regulation.

Recent work from our lab has led to further understanding of the underlying mechanisms of TbRAP1-mediated VSG silencing. First, silencing appears to depend on the association of TbRAP1 with the local chromatin, as more TbRAP1 proteins seem to associate with silent BESs than the active B-ES in the same BF cells when analyzed by ChIP (Unnati P. \& Li B., unpublished data). This is consistent with the observation that proximity to telomeres leads to stronger TbRAP1-mediated silencing, as TbRAP1 is an intrinsic part of the telomere complex. Second, depletion of TbRAP1 resulted in more loosely packed chromatin structure at the silent B-ESs in PF cells: using a FAIRE (Formaldehyde-Assisted Isolation of Regulatory Elements) approach, more silent B-ES-linked VSG DNA can be extracted after depletion of TbRAP1 than in wild-type cells, indicating fewer nucleosomes are packed in the chromatin after B-ESs are derepressed. Although the details of histone modifications at the silent or derepressed B-ESs are unknown, this finding suggests that the TbRAP1-mediated VSG silencing is similar to ScRap1-mediated TPE in yeast, both involves establishment of heterochromatin structure at the telomere vicinity. 
Therefore, studies on the functions of T. brucei telomere proteins have finally proved the hypothesis and clearly shown that the telomere structure is important for subtelomeric VSG silencing. However, the involvement of telomere in VSG expression regulation does not necessarily exclude other mechanisms mentioned above. In fact, TbRAP1-mediated silencing appears to block the elongation of the basal level transcription from the silent B-ES promoters, because in TbRAP1 deficient cells, derepressed VSGs are expressed at a level that is still $\sim 100$ fold lower than when the same VSG is in a fully active B-ES (Yang et al. 2009). Therefore, the observed quick attenuation of transcription elongation along silent B-ESs may well be the combined effect of a basal level transcription initiated from silent B-ES promoters and a TbRAP1-mediated TPE. The fact that derepressed VSGs are not expressed at its fullest potential also suggests that B-ES promoters are regulated by additional factors other than TPE. This is consistent with the observations that a number of chromatin remodeling factors are involved in B-ES promoter regulation as mentioned above.

Recent studies have made great contributions to our understanding of how VSG expression is silenced. However, how is allelic-exclusive expression of VSG achieved is not fully understood. It has been proposed that sufficient amount of RNAP I machinery, which is responsible for high level VSG transcription, may be accessible for only one B-ES, which would effectively ensure its monoallelic expression (Horn \& McCulloch 2010). In an IF analysis, Navarro and Gull found that in BF T. brucei cells, RNAP I forms a small nuclear focus in addition to the large focus inside the nucleolus, where it transcribes rRNA. By labeling nascent RNA with Br-UTP, they confirmed that the extranucleolar RNAP I was transcriptionally active. Furthermore, by tagging the active B-ES with an array of Lac operator sequences and expressing an ectopic GFP-Lac I fusion protein, they were able to visualize that the active B-ES but not the silent ones is co-localized with RNAP I in this extranucleolar body termed ES body (ESB), which only exists in BF but not PF cells (Navarro \& Gull 2001). It is therefore hypothesized that ESB, enriched with RNAP I, can only accommodate one B-ES, which would effectively limit the number of active B-ES to one. In support of this view, when two different B-ESs were tagged with selective markers immediately downstream of their respective promoters and forced to be active simultaneously, the two B-ESs appear to switch back and force rapidly and locate next to each other in the nucleus, presumably competing for available RNAP I at ESB (Chaves et al. 1999).

\subsection{Telomere proteins influence VSG switching frequency in T. brucei}

As mentioned above, antigenic variation in T. brucei has two major aspects: monoallelic VSG expression and VSG switching. We have discussed about monoallelic VSG expression regulation above. Here we will review mechanisms involved in VSG switching and its regulation.

VSG switching can occur through several different pathways (Fig. 8) (Barry \& McCulloch 2001). In the so-called in situ switch, a silent B-ES promoter is turned fully active while the originally active B-ES promoter is turned off. This type of switch does not involve any DNA rearrangements, only B-ES promoter activities change. There are 15 B-ESs carrying distinctive VSGs in the T. brucei Lister 427 cells, providing a small number of possible in situ switch opportunities (Hertz-Fowler et al. 2008). However, in situ VSG switching is usually a rare event, and VSG switching involving DNA recombination events are much more 
prevalent (Robinson et al. 1999). T. brucei has more than 1,500 VSG genes and pseudogenes in its genome (Fig. 7), providing a large gene pool for the homologous recombinationmediated VSG switching (Berriman et al. 2005).

There are 11 pairs of megabase chromosomes (0.9-5.7 Mb), several intermediate chromosomes (300-900 kb), and $\sim 100$ copies of minichromosomes (50-100 kb) in T. brucei genome (Alsford et al. 2001; Berriman et al. 2005; Melville et al. 2000). The majority of VSG genes are found in long tandem arrays of repeated genes at subtelomeric locations on megabase chromosomes (Fig. 7C). Approximately 200 copies of VSG genes are found immediately upstream of telomeres of the minichromosomes, which carry besides the VSG genes, only repetitive sequences, including $177 \mathrm{bp}$ repeats in the chromosome internal region and telomere repeats at the chromosome ends (Fig. 7D) (Alsford et al. 2001). The rest of VSGs are found in VSG expression sites. In addition to the 15-20 copies of B-ESs located at megabase and intermediate chromosomes that express VSG at the bloodstream form stage (Fig. 7A), there are several hundred copies of metacyclic VSG ESs (M-ESs), and 1-2\% of which are expressed at the metacyclic stage (Fig. 7B) (Graham et al. 1998; Turner et al. 1988). Similar to B-ESs, M-ESs are located at subtelomeric regions of megabase chromosomes. However, unlike B-ESs, M-ESs are monocistronic transcription units, and their individual promoter is only $\sim 5 \mathrm{~kb}$ upstream of the telomere repeats (Pedram \& Donelson 1999). The VSG genes found in subtelomeric gene arrays and at minichromsome subtelomeres are often referred to as basic VSG copies because these loci are transcriptional silent. However, these basic VSG genes can be copied into the active B-ES via DNA recombination (Fig. 8).

In gene conversion events, a silent VSG is copied into the active B-ES while the originally active VSG is lost. In this event, the donor can be any functional VSG gene in the genome. There is almost always a stretch of $70 \mathrm{bp}$ repeats upstream of a VSG gene, in which homologous recombination can initiate as DNA double strand breaks (Boothroyd et al. 2009). In rare occasions, several VSG donors have been identified in a single VSG switching event, where each donor contributes only a fragment of the gene, generating a new mosaic VSG gene product (Marcello \& Barry 2007). Such mechanism has been proposed to be useful in late stage of persistent infection. More often, a silent B-ES is used as a donor possibly because long stretch of $70 \mathrm{bp}$ repeats $(2$ to $>14 \mathrm{~kb})$ and telomere repeats $(3$ to $20 \mathrm{~kb})$ are found to flank the VSG gene in any B-ES, and efficient homologous recombination can initiate from these sites. In fact, all B-ESs have very similar genome organization and are $\sim 90 \%$ identical in sequences, so gene conversion event can initiate at places upstream of 70 bp repeats and often a whole silent B-ES can be copied to replace the active B-ES (HertzFowler et al. 2008; Pays et al. 1983b). Therefore, the terms of VSG gene conversion and ES gene conversion are used to differentiate different types of gene conversion events (Kim \& Cross 2010). In addition to gene conversion, reciprocal crossover event can occur in a VSG switching (Rudenko et al. 1996). In this case, the crossover usually occurs at the $70 \mathrm{bp}$ repeats, and the silent and active VSGs (often together with their respective downstream telomeres) simply trade places without deletion of large fragments of genetic information. It is worth to note that in a crossover switching, the originally silent VSG often comes from a silent B-ES, but it can also be from a minichromosome subtelomere.

It has been shown that some key players in the homologous DNA recombination pathway including TbRAD51 and TbBRCA2 are important for VSG switching in T. brucei (McCulloch \& Barry 1999). In homologous recombination, searching for DNA sequence homology and 


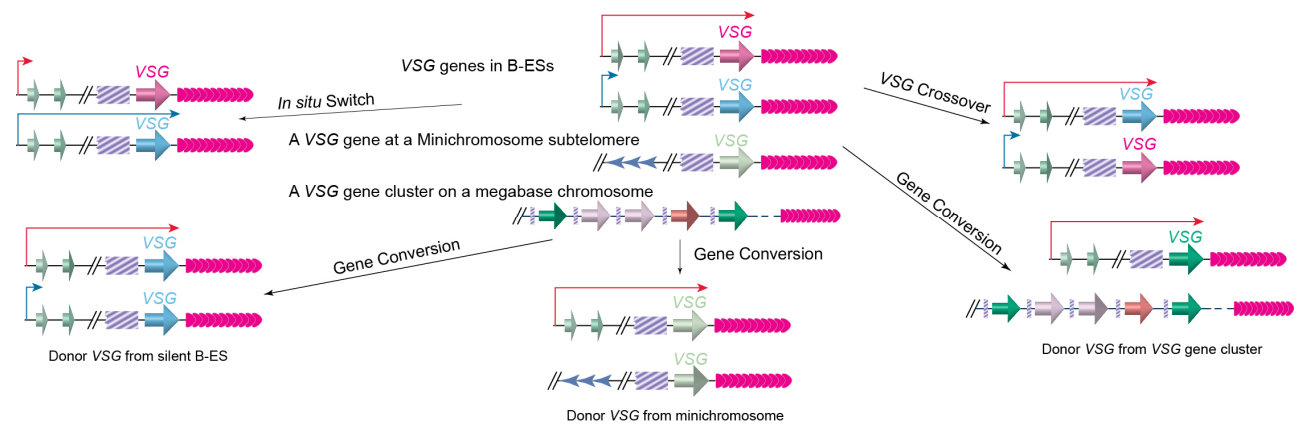

Fig. 8. VSG switching can occur through in situ switch, gene conversion, or crossover. Top Middle, before switching, an active B-ES (with a longer red arrows extended from its promoter), a silent B-ES (with a shorter blue arrow extended from its promoter), a VSG gene at a minichromosome subtelomere, and an array of VSG genes and pseudogenes on a megabase chromosome are shown. In situ switch (top left) results from turning on (longer blue arrow) of the silent B-ES and turning off (shorter red arrow) of the active B-ES simultaneously without any DNA rearrangements. In gene conversion, a silent VSG gene is duplicated into the active B-ES, and the originally active VSG gene is lost. The VSG donor can come from a silent B-ES (bottom-left), a minichromosome subtelomere (bottom-middle), or a VSG gene array (bottom-right). In VSG cross-over (top-right), the active VSG and a silent VSG (most often from a silent B-ES) exchange their loci reciprocally, resulting in a new VSG gene in the active B-ES without losing any genetic information. The cross-over site is often found within the $70 \mathrm{bp}$ repeats upstream of the VSG genes, although it can locate more upstream because all B-ES have high sequence homology.

subsequent strand-invasion is a key step. In eukaryotes, the RecA homolog RAD51 is the key player in this step (Holthausen et al. 2010). RAD51 polymerizes around ssDNA to assemble a nucleoprotein helical filament (Holloman 2011). With the help of ATP, RAD51 extends the DNA structure and carries out the strand exchange process. After ATP is hydrolyzed, the extended state is relieved and the filament is disassembled. Factors contributing to filament assembly and disassembly thus provide a means for regulating homologous recombination. When ssDNA is coated with RPA (a single strand-specific DNA binding protein), it will not be accessible by RAD51 without the help of a mediator, such as BRCA2 (Holloman 2011). In T. brucei, six RAD51 related proteins have been identified: RAD51, DMC1, RAD51-3, RAD51-4, RAD51-5, and Rad51-6 (Proudfoot \& McCulloch 2005). Among these, deletion of TbRAD51 and TbRAD51-3 led to a decrease in VSG switching rate while deletion of TbRAD51-5 did not have any effect (Proudfoot \& McCulloch 2005). In addition, deletion of TbBRCA2 also led to a similar decreased VSG switching rate (Hartley \& McCulloch 2008).

Homologous recombination is important for the repair of ssDNA gaps, double-strand breaks, and stalled replication forks that arise during DNA synthesis. However, aberrant and inappropriate mitotic homologous recombination, such as high frequency of sister chromatid exchanges, posts a threat to genome stability. The RecQ helicase BLM (or Sgs1 in yeast) forms a complex with type 1A topoisomerase TOPO III (or Top3 in yeast) and an OB fold containing RMI1 (Mankouri \& Hickson 2007). This so-called RTR complex has been shown to suppress aberrant and inappropriate homologous recombination. It has been 
shown recently that in T. brucei, the homologues of TOPO3 and RMI1 also form a complex (Kim \& Cross 2011). In addition, both TbTOPO3a and TbRMI1 are involved in regulation of VSG switching (Kim \& Cross 2010, 2011). Deletion of TbTOPO3a or TbRMI1 led to 10-40 or $\sim 4$ fold of increase, respectively, in VSG switching frequency. Particularly, the VSG gene conversion frequency was increased more than 10 fold in either TbTOPO3a null or TbRMI1 null cells. These observations suggest that the TbTOPO3a and TbRMI1 complex is important to suppress aberrant homologous recombination to maintain integrity of the active VSG BES.

Apparently, homologous recombination is a major pathway for VSG switching. In fact, it has been shown that gene conversion is the preferred mechanism for VSG switching (Robinson et al. 1999). However, exactly how VSG switching is regulated is less clear. Several recent studies now indicate that the telomere structure can also influence VSG switching greatly.

It has been shown that the active VSG-marked telomere is less stable than the silent telomeres (Bernards et al. 1983; Horn \& Cross 1997; Myler et al. 1988; Pays et al. 1983a; van der Ploeg et al. 1984). Rapidly shortened active telomere arises frequently, which is quite similar to the TRD observed in yeast cells carrying abnormally long telomeres (Li \& Lustig 1996). Presumably the active transcription of the telomere is a major cause for the brittle telomere (Rudenko \& Van der Ploeg 1989). With the presence of telomerase, shortened telomeres are elongated quickly (Horn et al. 2000). With frequent truncation and elongation, telomere length at the active chromosome end is often much more heterogeneous than those at silent telomeres (Bernards et al. 1983). However, in the absence of telomerase, the truncated active telomere remains short, allowing the isolation of clones baring extremely short active telomere in a relatively short culturing period (Dreesen \& Cross 2006a). Interestingly, when such telomerase negative clones were obtained that carry extremely short active telomere, these clones tend to switch to express a new VSG (Dreesen \& Cross 2006a). This observation led to the hypothesis that shorter telomeres may cause higher VSG switching rate (Dreesen et al. 2007). It is speculated that all active telomeres are prone to large telomere fragment deletions due to its active transcription state, but shorter telomeres is more likely to have a deletion landed in the subtelomeric region and to cause damage in the active VSG gene, which will force the parasite to go through VSG switching. Introducing a break at the I-SCE I site targeted immediately upstream of the active VSG gene led to a 250-fold increase in VSG switching frequency, confirming part of this theory that damage to the active VSG gene will force the parasite to switch (Boothroyd et al. 2009). In consistent with this observation, deplete the active VSG using the RNAi approach also led to elevated VSG switching rate (Aitcheson et al. 2005).

Whether telomere length plays a direct role in VSG switching is harder to confirm. In consistence with the hypothesis, several T. brucei strains with only limited propagation in a laboratory (usually called pleomorphic strains) have much higher VSG switching rate $\left(10^{-4}\right.$ to $10^{-2}$ per population doubling) and relatively shorter telomeres (3-12 kb long, with an average of 8-10 kb) (Dreesen \& Cross 2008). In contrast, the 427 Lister strain has been extensively propagated in the laboratory, has a VSG switch rate of $10^{-6}$ per generation, and has telomeres ranging 3-20 kb with an average of $15 \mathrm{~kb}$ (Munoz-Jordan \& Cross 2001). More direct evidence supporting this theory came from a recent study using newly developed MACS-based VSG switching analysis: in 427 Lister strain, in telomerase null cells that most 
telomeres are very short (less than $2 \mathrm{~kb}$ ), the VSG switching frequency was increased $\sim 10$ fold compared to wild-type cells carrying long telomeres, confirming that the telomere length does influence VSG switching (Cross GAM \& Papavasiliou FN, personal communications). However, telomere length is probably only one of many reasons for the high VSG switching rate in the pleomorphic strains: The telomerase null 427 strain has extremely short telomeres (as short as $\sim 40 \mathrm{bp}$ ), but the VSG switching rate is only 10 fold elevated; The telomeres in the pleomorphic strains are only a little shorter than those in the 427 strain (8-10 kb vs $15 \mathrm{~kb}$ on average), but the VSG switching rate is $100-10,000$ fold higher in pleomorphic cells than in the 427 strain.

In addition to telomere length, our recent studies indicated that telomere-specific proteins play important roles in antigenic variation. Using a double-marked cell line established by Kim and Cross (Kim \& Cross 2010), we were able to estimate VSG switching rate and examine switching pathways in T. brucei cells depleted of individual telomere proteins. In this switching reporter cell line, a blasticidin-resistance gene $(B S D)$ had been inserted at the promoter driving the VSG2 B-ES and a puromycin-resistance gene fused to the Herpes simplex virus thymidine kinase (PUR-TK) downstream of the 70-bp repeats in the same B-ES (Fig. 9). VSG switchers are expected to lose the PUR-TK marker or repress PUR-TK expression, making cells resistant to ganciclovir (GCV). After VSG switching, the mechanism of switching can also be determined by examination of various markers. In-situ switching occurs by inactivating the active B-ES and activating one of silent B-ESs. Therefore, in-situ switchers will preserve BSD and VSG2 genes but repress their expression. ES gene conversion occurs through recombination near the B-ES promoter, which allows duplication and translocation of an entire silent B-ES to the VSG2 subtelomere. These switchers will lose BSD and VSG2 genes. Recombination near VSGs can result in either duplicative gene conversion of a new VSG to the VSG2 B-ES (VSG gene conversion) or in $V S G$ crossover switching. In both cases, the BSD gene will be at the active promoter, but these two recombinants can be distinguished by VSG2 absence (VSG gene conversion) or presence (crossover).

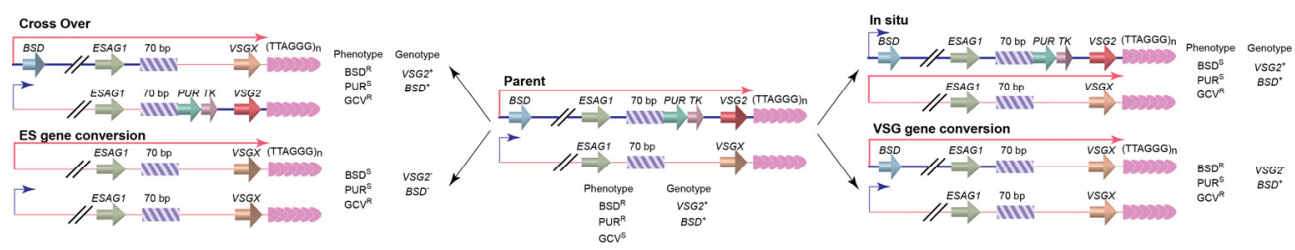

Fig. 9. Strategy for analyzing VSG switching in a double-marked T. brucei cell line. The parent cell line is shown in the center. Several different switching events are shown on either side.

In T. brucei, TbTRF is the duplex telomere DNA binding factor (Li et al. 2005), and it associates with TbTIN2. TbTIN2 was also observed to be localized at telomeres by IF and ChIP analyses, and TbTIN2 interacts with TbTRF in vivo in co-IP experiments, indicating that TbTIN2 is an intrinsic component of the T. brucei telomere complex (Jehi S. \& Li B. unpublished data). Using the above described VSG switching assay, we observed that a transient depletion of TbTIN2 led to an $\sim 3.8$ fold increase in VSG switching frequency. In addition, 93\% of all switching events are ES gene conversion in TbTIN2 deficient cells 
compared to $80 \%$ of the switchers were resulted from ES gene conversion in wild-type cells. Because TbTIN2 is essential for cell viability, it is only transiently depleted in the experiment so that switchers can be recovered. Therefore, the phenotype in true TbTIN2 null cells is expected to be more severe. TbTRF appears to have a similar influence on VSG switching (Benmerzouga I. \& Li B., unpublished data). We have established viable cell lines that express a single TbTRF allele with a point mutation in its DNA binding myb domain. In vitro Isothermal Titration Calorimetry (ITC) analysis and in vivo ChIP analysis both confirmed that the mutant TbTRF has a severely reduced telomere DNA binding activity (Zhao Y., Benmerzouga I. \& Li B., unpublished data). VSG switching frequency is $\sim 3$ fold higher in the TbTRF mutant than in wild-type cells. In the TbTRF mutant, $41 \%$ of the switchers were VSG gene conversion events compared to only $8 \%$ in wild-type cells. Depletion of another telomere protein, TbRAP1, also led to $>7$ fold of increase in VSG switching frequency, and $65 \%$ of all switchers resulted from VSG gene conversions, but only $30 \%$ of switchers resulted from ES gene conversion (Nanavaty V. \& Li B., unpublished data). Depleting of TbRAP1 also led to derepression of subtelomeric VSGs (Yang et al. 2009), which is not observed in TbTRF or TbTIN2 deficient cells. Therefore, TbRAP1 appears to regulate VSG expression and VSG switching differently from TbTRF and TbTIN2.

These preliminary data indicate that the telomere structure is not only important for proper VSG silencing but also plays an important role in regulating VSG switching rate. It is possible that disruption of the heterochromatic telomere structure, especially in the case of depletion of TbRAP1, elevated subtelomeric homologous recombination and led to higher VSG switching rate, similar to what was observed in S. pombe (Bisht et al. 2008).

\subsection{Does telomere affect switching of subtelomere-located surface antigen in $P$. carinii and $B$. burgdorferi?}

Pneumocystis carinii is a fungus that solely dwells in the lung tissue of mammals. Normally, $P$. carinii infection does not cause any symptom, but in immunocompromised individuals it can cause pneumonia. The complete life cycle of $P$. carinii is still not very well defined, mainly because of the lack of a continuous cultivation system. However, it is obvious that $P$. carinii can survive in the lower respiratory tract where strong and effective defense systems normally work to eliminate invaders, and the reason for persistent and effective $P$. carinii infection is that it undergoes antigenic variation at a high frequency (Cushion \& Stringer 2010).

The major surface glycoprotein (MSG) is one of the major surface molecules of $P$. carinii that is involved in antigenic variation (Stringer 2005). MSG is encoded by the MSG gene family. So far 73 MSG genes have been identified, all are located at the subtelomeric loci (Fig. 10) (Keely \& Stringer 2009). There are 17 chromosomes in P. carinii (Hong et al. 1990), indicating that on average at least 2 MSG genes are at each telomere, which is often the case in cloned terminal fragments from various chromosomes (Keely et al. 2005; Wada \& Nakamura 1996). Similar to the situation in T. brucei, only one MSG gene is transcribed at any time. Transcribed MSG messengers always contained an upstream conserved sequence (UCS) (Edman et al. 1996; Sunkin \& Stringer 1997; Wada \& Nakamura 1996; Wada et al. 1995), which has only one copy in the P. carinii genome (Edman et al. 1996; Wada et al. 1995), suggesting that MSG is transcribed from a specific expression site marked with the unique UCS element. In addition, translation initiation codon on an MSG mRNA is located in the 
sequence transcribed from the UCS (Edman et al. 1996; Wada et al. 1995). Therefore, transcribing MSG from UCS-containing expression site is essential for proper MSG translation. Furthermore, the UCS encoded peptide contains a signal sequence that targets the pre-MSG protein into the endoplasmic reticulum, where it can be cleaved and glycosylated, then deposited on the cell surface (Sunkin et al. 1998). Hence the UCS peptide is also essential for MSG function, although it is not present on MSG found on the cell surface because it is likely removed in the endoplasmic reticulum.

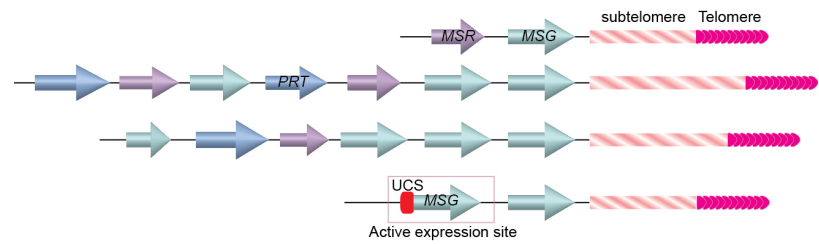

Fig. 10. Gene arrays at the ends of three Pneumocystis carinii chromosomes. MSG genes (cyan colored arrows) are located closest to the telomere and subtelomeric repetitive sequences. A single copy UCS is found in the active MSG expression site immediately upstream of the MSG gene.

If $P$. carinii contains only one UCS-containing MSG expression site, how does it achieve antigenic variation? Computational analysis of MSG gene sequences suggested that these genes commonly undergo recombination (Keely \& Stringer 2009; Keely et al. 2005; Wada \& Nakamura 1996), which is not unlike the VSG switching in T. brucei. Similar to VSG, MSG is also the last transcribed gene on the chromosome (Keely et al. 2005; Wada \& Nakamura 1996). The proximity of MSG genes to telomeres suggests that the MSG switching events might also be regulated by the telomere structure, although this has not be investigated at all.

In a different microbial pathogen Borrelia burgdorferi, the spirochete that causes the Lyme disease, the gene encoding variant surface antigen is found at a subtelomere region on a linear plasmid (Zhang et al. 1997). B. burgdorferi also undergoes antigenic variation, and the liproprotein VlsE is the variant surface protein (Norris 2006; Schwan et al. 1991; Steere et al. 2004; Zhang \& Norris 1998a; Zhang et al. 1997). VlsE is encoded by the vls gene family located on the linear plasmid lp28-1 (Fig. 11). Immediately next to the telomere is the active $v l s E$ expression site. More upstream is the silent $v l s$ gene cluster (Zhang et al. 1997). Bacteria lost the lp28-1 exhibit an intermediate infectivity phenotype where it is hard to establish a persistent infection in the mouse model (Bankhead \& Chaconas 2007). Deletion of vlsE and silent $v l s$ cassettes also led to reduced persistent infection, indicating that antigenic variation through $v l s$ switching is an important virulence mechanism in B. burgdorferi (Bankhead \& Chaconas 2007; Labandeira-Rey \& Skare 2001; Purser \& Norris 2000; Zhang et al. 1997). The vls $E$ and the silent $v l s$ genes are highly homologous at the sequence level, and most of the sequence differences within the cassette regions are concentrated in six variable regions, VR1-VR6 (Zhang \& Norris 1998b). Segmental gene conversion between the silent cassettes and the $v l s E$ cassette region occurs as early as 4 days after infection in mice, and appears to continue throughout the course of infection (Zhang \& Norris 1998a). Because these recombination events appear to involve random segments of any silent cassette and occur continuously during infection, an almost unlimited number of $V l s E$ amino acid sequence 
permutations are theoretically possible (Zhang \& Norris 1998b). Apparently, vls switching is not so unlike the VSG switching in T. brucei or MSG switching in P. carinii. However, nothing is known about the telomere structure at the ends of 1 p28 or any protein(s) associated with it. Therefore, it is unclear whether the nearby telomere structure might exhibit any influence to $v l s$ switching.

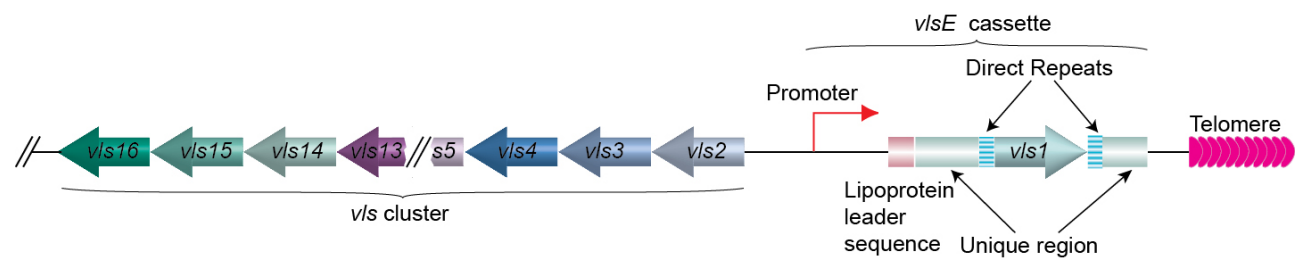

Fig. 11. The organization of $v l s E$ and the array of silent $v l s$ genes on $1 \mathrm{p} 28$ linear plasmid of $B$. burgdorferi. The $v l s 1$ gene (moss colored arrow) is expressed from the $v l s E$ expression site next to the telomere (pink arrows). The direct repeats (barred boxes) and the unique regions (green boxes) flanking the vls1 gene and the lipoprotein leader sequence (rouge box) upstream of $v l s 1$ are marked. The silent array includes $v l s$ 2-16 genes (various colored arrows) going to the opposite direction from $v l s 1$ are located at the internal region of the linear plasmid.

\section{Conclusions}

In many organisms, telomere forms a specialized heterochromatic structure that can influence the expression of genes located nearby. It appears that a number of microbial pathogens have conveniently taken advantage of this telomere position effect to regulate expression of surface antigen-encoding gene families at subtelomeric regions. Further studies of the telomere structure and telomere specific proteins in these microbial pathogens should provide more insight about the allelic exclusion expression of surface antigen genes. Similarly, the subtelomeric region in many eukaryotic cells appear to be a recombination hot spot, which has been proposed to contribute to gene diversity. This could be one of the reasons why many gene families encoding virulence factors are located at subtelomeric loci. One cannot help to speculate that the intrinsic plastic nature of the subtelomeres might facilitate antigenic variation. On the other hand, unchecked homologous recombination could cause hazardous genome instability, and the telomere structure with telomere-specific proteins appears to suppress subtelomeric recombination to maintain a relatively stable genome organization.

\section{References}

Abad, J. P.; De Pablos, B.; Osoegawa, K.; De Jong, P. J.; Martin-Gallardo, A. et al. 2004. TAHRE, a novel telomeric retrotransposon from Drosophila melanogaster, reveals the origin of Drosophila telomeres. Mol Biol Evol 21: 1620-1624.

Aitcheson, N.; Talbot, S.; Shapiro, J.; Hughes, K.; Adkin, C. et al. 2005. VSG switching in Trypanosoma brucei: antigenic variation analysed using RNAi in the absence of immune selection. Mol Microbiol 57: 1608-1622. 
Alsford, S.; Kawahara, T.; Isamah, C. \& Horn, D. 2007. A sirtuin in the African trypanosome is involved in both DNA repair and telomeric gene silencing but is not required for antigenic variation. Mol Microbiol 63: 724-736.

Alsford, S.; Wickstead, B.; Ersfeld, K. \& Gull, K. 2001. Diversity and dynamics of the minichromosomal karyotype in Trypanosoma brucei. Mol. Biochem. Parasitol. 113: 7988.

Altaf, M.; Utley, R. T.; Lacoste, N.; Tan, S.; Briggs, S. D. et al. 2007. Interplay of chromatin modifiers on a short basic patch of histone $\mathrm{H} 4$ tail defines the boundary of telomeric heterochromatin. Mol Cell 28: 1002-1014.

Andreyeva, E. N.; Belyaeva, E. S.; Semeshin, V. F.; Pokholkova, G. V. \& Zhimulev, I. F. 2005. Three distinct chromatin domains in telomere ends of polytene chromosomes in Drosophila melanogaster Tel mutants. J Cell Sci 118: 5465-5477.

Andrulis, E. D.; Neiman, A. M.; Zappulla, D. C. \& Sternglanz, R. 1998. Perinuclear localization of chromatin facilitates transcriptional silencing. Nature 394: 592-595.

Aparicio, O. M.; Billington, B. L. \& Gottschling, D. E. 1991. Modifiers of position effect are shared between telomeric and silent mating-type loci in S. cerevisiae. Cell 66: 12791287.

Bailey, S. M.; Cornforth, M. N.; Kurimasa, A.; Chen, D. J. \& Goodwin, E. H. 2001. Strandspecific Postreplicative Processing of Mammalian Telomeres. Science 2462-2465.

Bailey, S. M.; Brenneman, M. A. \& Goodwin, E. H. 2004. Frequent recombination in telomeric DNA may extend the proliferative life of telomerase-negative cells. Nucleic Acids Res 32: 3743-3751.

Bankhead, T. \& Chaconas, G. 2007. The role of VlsE antigenic variation in the Lyme disease spirochete: persistence through a mechanism that differs from other pathogens. Mol Microbiol 65: 1547-1558.

Barry, J. D. \& McCulloch, R. 2001. Antigenic variation in trypanosomes: enhanced phenotypic variation in a eukaryotic parasite. Adv Parasitol 49: 1-70.

Baruch, D. I.; Pasloske, B. L.; Singh, H. B.; Bi, X.; Ma, X. C. et al. 1995. Cloning the P. falciparum gene encoding PfEMP1, a malarial variant antigen and adherence receptor on the surface of parasitized human erythrocytes. Cell 82: 77-87.

Baruch, D. I. 1999. Adhesive receptors on malaria-parasitized red cells. Baillieres Best Pract Res Clin Haematol 12: 747-761.

Baumann, P. \& Cech, T. R. 2001. Pot1, the putative telomere end-binding protein in fission yeast and humans. Science 292: 1171-1175.

Baur, J. A.; Zou, Y.; Shay, J. W. \& Wright, W. E. 2001. Telomere position effect in human cells. Science 292: 2075-2077.

Benetti, R.; Gonzalo, S.; Jaco, I.; Schotta, G.; Klatt, P. et al. 2007. Suv4-20h deficiency results in telomere elongation and derepression of telomere recombination. J Cell Biol 178: 925-936.

Bernards, A.; Michels, P. A. M.; Lincke, C. R. \& Borst, P. 1983. Growth of chromosome ends in multiplying trypanosomes. Nature 303: 592-597.

Berriman, M.; Ghedin, E.; Hertz-Fowler, C.; Blandin, G.; Renauld, H. et al. 2005. The genome of the African trypanosome Trypanosoma brucei. Science 309: 416-422.

Biessmann, H.; Valgeirsdottir, K.; Lofsky, A.; Chin, C.; Ginther, B. et al. 1992. HeT-A, a transposable element specifically involved in "healing" broken chromosome ends in Drosophila melanogaster. Mol Cell Biol 12: 3910-3918. 
Biessmann, H.; Kasravi, B.; Bui, T.; Fujiwara, G.; Champion, L. E. et al. 1994. Comparison of two active HeT-A retroposons of Drosophila melanogaster. Chromosoma 103: 90-98.

Biessmann, H.; Prasad, S.; Semeshin, V. F.; Andreyeva, E. N.; Nguyen, Q. et al. 2005. Two distinct domains in Drosophila melanogaster telomeres. Genetics 171: 1767-1777.

Bilaud, T.; Brun, C.; Ancelin, K.; Koering, C. E.; Laroche, T. et al. 1997. Telomeric localization of TRF2, a novel human telobox protein. Nat. Genet. 17: 236-239.

Bisht, K. K.; Arora, S.; Ahmed, S. \& Singh, J. 2008. Role of heterochromatin in suppressing subtelomeric recombination in fission yeast. Yeast 25: 537-548.

Boivin, A.; Gally, C.; Netter, S.; Anxolabehere, D. \& Ronsseray, S. 2003. Telomeric associated sequences of Drosophila recruit polycomb-group proteins in vivo and can induce pairing-sensitive repression. Genetics 164: 195-208.

Boothroyd, C. E.; Dreesen, O.; Leonova, T.; Ly, K. I.; Figueiredo, L. M. et al. 2009. A yeastendonuclease-generated DNA break induces antigenic switching in Trypanosoma brucei. Nature 459: 278-281.

Bork, P.; Hofmann, K.; Bucher, P.; Neuwald, A. F.; Altschul, S. F. et al. 1997. A superfamily of conserved domains in DNA damage-responsive cell cycle checkpoint proteins. FASEB J. 11: 68-76.

Boscheron, C.; Maillet, L.; Marcand, S.; Tsai-Pflugfelder, M.; Gasser, S. M. et al. 1996. Cooperation at a distance between silencers and proto-silencers at the yeast HML locus. EMBO J 15: 2184-2195.

Boulton, S. J. \& Jackson, S. P. 1998. Components of the Ku-dependent non-homologous endjoining pathway are involved in telomeric length maintenance and telomeric silencing. EMBO J. 17: 1819-1828.

- - - 1996. Identification of a Saccharomyces cerevisiae Ku80 homologue: roles in DNA double strand break rejoining and in telomeric maintenance. Nucleic Acids Res 24: 4639-4648.

Bourns, B. D.; Alexander, M. K.; Smith, A. M. \& Zakian, V. A. 1998. Sir proteins, Rif proteins, and Cdc13p bind Saccharomyces telomeres in vivo. Mol Cell Biol 18: 5600-5608.

Broadbent, K. M.; Park, D.; Wolf, A. R.; Van Tyne, D.; Sims, J. S. et al. 2011. A global transcriptional analysis of Plasmodium falciparum malaria reveals a novel family of telomere-associated lncRNAs. Genome Biol 12: R56.

Broccoli, D.; Smogorzewska, A.; Chong, L. \& de Lange, T. 1997. Human telomeres contain two distinct Myb-related proteins, TRF1 and TRF2. Nat. Genet. 17: 231-235.

Brown, W. R.; MacKinnon, P. J.; Villasante, A.; Spurr, N.; Buckle, V. J. et al. 1990. Structure and polymorphism of human telomere-associated DNA. Cell 63: 119-132.

Bryan, T. M.; Englezou, A.; Gupta, J.; Bacchetti, S. \& Reddel, R. R. 1995. Telomere elongation in immortal human cells without detectable telomerase activity. Embo J 14: 42404248.

Bryan, T. M.; Englezou, A.; Dalla-Pozza, L.; Dunham, M. A. \& Reddel, R. R. 1997. Evidence for an alternative mechanism for maintaining telomere length in human tumors and tumor-derived cell lines [see comments]. Nat Med 3: 1271-1274.

Buchberger, J. R.; Onishi, M.; Li, G.; Seebacher, J.; Rudner, A. D. et al. 2008. Sir3-nucleosome interactions in spreading of silent chromatin in Saccharomyces cerevisiae. Mol Cell Biol 28: 6903-6918. 
Buck, S. W. \& Shore, D. 1995. Action of a RAP1 carboxy-terminal silencing domain reveals an underlying competition between HMR and telomeres in yeast. Genes Dev 9: 370384.

Calderwood, M. S.; Gannoun-Zaki, L.; Wellems, T. E. \& Deitsch, K. W. 2003. Plasmodium falciparum var genes are regulated by two regions with separate promoters, one upstream of the coding region and a second within the intron. J Biol Chem 278: 34125-34132.

Callebaut, I. \& Mornon, J. P. 1997. From BRCA1 to RAP1: a widespread BRCT module closely associated with DNA repair. FEBS Lett. 400: 25-30.

Cam, H. P.; Sugiyama, T.; Chen, E. S.; Chen, X.; FitzGerald, P. C. et al. 2005. Comprehensive analysis of heterochromatin- and RNAi-mediated epigenetic control of the fission yeast genome. Nat Genet 37: 809-819.

Carlson, M. \& Botstein, D. 1983. Organization of the SUC gene family in Saccharomyces. Mol Cell Biol 3: 351-359.

Carlson, M.; Celenza, J. L. \& Eng, F. J. 1985. Evolution of the dispersed SUC gene family of Saccharomyces by rearrangements of chromosome telomeres. Mol Cell Biol 5: 28942902.

Castano, I.; Pan, S. J.; Zupancic, M.; Hennequin, C.; Dujon, B. et al. 2005. Telomere length control and transcriptional regulation of subtelomeric adhesins in Candida glabrata. Mol Microbiol 55: 1246-1258.

Cenci, G.; Siriaco, G.; Raffa, G. D.; Kellum, R. \& Gatti, M. 2003. The Drosophila HOAP protein is required for telomere capping. Nat Cell Biol 5: 82-84.

Chakrabarty, S. P.; Saikumari, Y. K.; Bopanna, M. P. \& Balaram, H. 2008. Biochemical characterization of Plasmodium falciparum Sir2, a NAD+-dependent deacetylase. Mol Biochem Parasitol 158: 139-151.

Chan, C. S. M. \& Tye, B.-K. 1983a. Organization of DNA sequences and replication origins at yeast telomeres. Cell 33: 563-573.

Chan, C. S. M. \& Tye, B.-K. 1983b. A family of Saccharomyces cerevisiae repetitive autonomously replicating sequences that have very similar genomic environments. JMB 168: 505-524.

Charron, M. J. \& Michels, C. A. 1988. The naturally occurring alleles of MAL1 in Saccharomyces species evolved by various mutagenic processes including chromosomal rearrangement. Genetics 120: 83-93.

Charron, M. J.; Read, E.; Haut, S. R. \& Michels, C. A. 1989. Molecular evolution of the telomere-associated MAL loci of Saccharomyces. Genetics 122: 307-316.

Chaves, I.; Rudenko, G.; Dirks-Mulder, A.; Cross, M. \& Borst, P. 1999. Control of variant surface glycoprotein gene-expression sites in Trypanosoma brucei. EMBO J 18: 48464855.

Chen, Y.; Rai, R.; Zhou, Z. R.; Kanoh, J.; Ribeyre, C. et al. 2011. A conserved motif within RAP1 has diversified roles in telomere protection and regulation in different organisms. Nat Struct Mol Biol

Cheng, Q.; Cloonan, N.; Fischer, K.; Thompson, J.; Waine, G. et al. 1998. stevor and rif are Plasmodium falciparum multicopy gene families which potentially encode variant antigens. Mol Biochem Parasitol 97: 161-176.

Chong, L.; van Steensel, B.; Broccoli, D.; Erdjument-Bromage, H.; Hanish, J. et al. 1995. A human telomeric protein. Science 270: 1663-1667. 
Chookajorn, T.; Dzikowski, R.; Frank, M.; Li, F.; Jiwani, A. Z. et al. 2007. Epigenetic memory at malaria virulence genes. Proc Natl Acad Sci U S A 104: 899-902.

Cifuentes-Rojas, C. \& Shippen, D. E. 2011. Telomerase regulation. Mutat Res

Cockell, M.; Palladino, F.; Laroche, T.; Kyrion, G.; Liu, C. et al. 1995. The carboxy termini of Sir4 and Rap1 affect Sir3 localization: Evidence for a multicomponent complex required for yeast telomeric silencing. J Cell Biol 129: 909-924.

Cooper, J. P.; Nimmo, E. R.; Allshire, R. C. \& Cech, T. R. 1997. Regulation of telomere length and function by a Myb-domain protein in fission yeast. Nature 385: 744-747.

Corcoran, L. M.; Thompson, J. K.; Walliker, D. \& Kemp, D. J. 1988. Homologous recombination within subtelomeric repeat sequences generates chromosome size polymorphisms in P. falciparum. Cell 53: 807-813.

Cormack, B. P.; Ghori, N. \& Falkow, S. 1999. An adhesin of the yeast pathogen Candida glabrata mediating adherence to human epithelial cells. Science 285: 578-582.

Cornelissen, A. W.; Bakkeren, G. A.; Barry, J. D.; Michels, P. A. \& Borst, P. 1985. Characteristics of trypanosome variant antigen genes active in the tsetse fly. NAR 13: 4661-4676.

Creamer, K. M. \& Partridge, J. F. 2011. RITS-connecting transcription, RNA interference, and heterochromatin assembly in fission yeast. Wiley Interdiscip Rev RNA 2: 632-646.

Critchlow, S. E. \& Jackson, S. P. 1998. DNA end-joining: from yeast to man. TIBS 23: 394-398.

Cross, S.; Lindsey, J.; Fantes, J.; McKay, S.; McGill, N. et al. 1990. The structure of a subterminal repeated sequence present on many human chromosomes. Nucleic Acids Res 18: 6649-6657.

Cryderman, D. E.; Morris, E. J.; Biessmann, H.; Elgin, S. C. \& Wallrath, L. L. 1999. Silencing at Drosophila telomeres: nuclear organization and chromatin structure play critical roles. EMBO J 18: 3724-3735.

Cushion, M. T. \& Stringer, J. R. 2010. Stealth and opportunism: alternative lifestyles of species in the fungal genus Pneumocystis. Annu Rev Microbiol 64: 431-452.

De Bruin, D.; Lanzer, M. \& Ravetch, J. V. 1994. The polymorphic subtelomeric regions of Plasmodium falciparum chromosomes contain arrays of repetitive sequence elements. Proc Natl Acad Sci Usa 91: 619-623.

de Lange, T. \& Borst, P. 1982. Genomic environment of the expression-linked extra copies of genes for surface antigens of Trypanosoma brucei resembles the end of a chromosome. Nature 299: 451-453.

de Lange, T.; Shiue, L.; Myers, R. M.; Cox, D. R.; Naylor, S. L. et al. 1990. Structure and variability of human chromosome ends. Mol. Cell. Biol. 10: 518-527.

de Lange, T. 2002. Protection of mammalian telomeres. Oncogene 21: 532-540.

--- . 2005. Shelterin: the protein complex that shapes and safeguards human telomeres. Genes Dev 19: 2100-2110.

De Las Penas, A.; Pan, S. J.; Castano, I.; Alder, J.; Cregg, R. et al. 2003. Virulence-related surface glycoproteins in the yeast pathogen Candida glabrata are encoded in subtelomeric clusters and subject to RAP1- and SIR-dependent transcriptional silencing. Genes Dev 17: 2245-2258.

Dehe, P. M. \& Cooper, J. P. 2010. Fission yeast telomeres forecast the end of the crisis. FEBS Lett 584: 3725-3733.

Deitsch, K. W.; Calderwood, M. S. \& Wellems, T. E. 2001. Malaria - Cooperative silencing elements in var genes. Nature 412: 875-876. 
Deitsch, K. W.; Lukehart, S. A. \& Stringer, J. R. 2009. Common strategies for antigenic variation by bacterial, fungal and protozoan pathogens. Nat Rev Microbiol 7: 493503.

DeMaria, S. \& Ngai, J. 2010. The cell biology of smell. J Cell Biol 191: 443-452.

Denninger, V.; Fullbrook, A.; Bessat, M.; Ersfeld, K. \& Rudenko, G. 2010. The FACT subunit TbSpt16 is involved in cell cycle specific control of VSG expression sites in Trypanosoma brucei. Mol Microbiol 78: 459-474.

Diffley, J. F. \& Stillman, B. 1989. Similarity between the transcriptional silencer binding proteins ABF1 and RAP1. Science 246: 1034-1038.

Domergue, R.; Castano, I.; De Las Penas, A.; Zupancic, M.; Lockatell, V. et al. 2005. Nicotinic acid limitation regulates silencing of Candida adhesins during UTI. Science 308: 866-870.

Dreesen, O. \& Cross, G. A. 2006a. Consequences of telomere shortening at an active VSG expression site in telomerase-deficient Trypanosoma brucei. Eukaryot. Cell 5: 21142119.

- - - 2006b. Telomerase-independent stabilization of short telomeres in Trypanosoma brucei. Mol. Cell. Biol. 26: 4911-4919.

Dreesen, O.; Li, B. \& Cross, G. A. M. 2007. Telomere structure and function in trypanosomes: a proposal. Nat Rev Microbiol 5: 70-75.

Dreesen, O. \& Cross, G. A. M. 2008. Telomere length in Trypanosoma brucei. Exp Parasitol 118: 103-110.

Driller, L.; Wellinger, R. J.; Larrivee, M.; Kremmer, E.; Jaklin, S. et al. 2000. A short Cterminal domain of Yku70p is essential for telomere maintenance. J Biol Chem 275: 24921-24927.

Dunham, M. A.; Neumann, A. A.; Fasching, C. L. \& Reddel, R. R. 2000. Telomere maintenance by recombination in human cells. Nat Genet 26: 447-450.

Duraisingh, M. T.; Voss, T. S.; Marty, A. J.; Duffy, M. F.; Good, R. T. et al. 2005. Heterochromatin silencing and locus repositioning linked to regulation of virulence genes in Plasmodium falciparum. Cell 121: 13-24.

Dzikowski, R.; Li, F.; Amulic, B.; Eisberg, A.; Frank, M. et al. 2007. Mechanisms underlying mutually exclusive expression of virulence genes by malaria parasites. EMBO Rep 8: 959-965.

Dzikowski, R. \& Deitsch, K. W. 2009. Genetics of antigenic variation in Plasmodium falciparum. Curr Genet 55: 103-110.

Edman, J. C.; Hatton, T. W.; Nam, M.; Turner, R.; Mei, Q. et al. 1996. A single expression site with a conserved leader sequence regulates variation of expression of the Pneumocystis carinii family of major surface glycoprotein genes. DNA Cell Biol 15: 989-999.

Ehrenhofer-Murray, A. E.; Rivier, D. H. \& Rine, J. 1997. The role of Sas2, an acetyltransferase homologue of Saccharomyces cerevisiae, in silencing and ORC function. Genetics 145: 923-934.

Eid, J. E. \& Sollner-Webb, B. 1995. ST-1, a 39-kilodalton protein in Trypanosoma brucei, exhibits a dual affinity for the duplex form of the 29-base-pair subtelomeric repeat and its C-rich strand. Mol Cell Biol 15: 389-397.

- - - . 1997. ST-2, a telomere and subtelomere duplex and G-strand binding protein activity in Trypanosoma brucei. J Biol Chem 272: 14927-14936. 
Ekwall, K.; Javerzat, J. P.; Lorentz, A.; Schmidt, H.; Cranston, G. et al. 1995. The chromodomain protein Swi6: a key component at fission yeast centromeres. Science 269: 1429-1431.

Epp, C.; Li, F.; Howitt, C. A.; Chookajorn, T. \& Deitsch, K. W. 2009. Chromatin associated sense and antisense noncoding RNAs are transcribed from the var gene family of virulence genes of the malaria parasite Plasmodium falciparum. RNA 15: 116-127.

Eugster, A.; Lanzuolo, C.; Bonneton, M.; Luciano, P.; Pollice, A. et al. 2006. The finger subdomain of yeast telomerase cooperates with Pif1p to limit telomere elongation. Nat Struct Mol Biol 13: 734-739.

Fanti, L.; Giovinazzo, G.; Berloco, M. \& Pimpinelli, S. 1998. The heterochromatin protein 1 prevents telomere fusions in Drosophila. Mol Cell 2: 527-538.

Feeser, E. A. \& Wolberger, C. 2008. Structural and functional studies of the Rap1 C-terminus reveal novel separation-of-function mutants. J Mol Biol 380: 520-531.

Feng, Q.; Wang, H.; Ng, H. H.; Erdjument-Bromage, H.; Tempst, P. et al. 2002. Methylation of H3-lysine 79 is mediated by a new family of HMTases without a SET domain. Curr Biol 12: 1052-1058.

Figueiredo, L. M.; Freitas-Junior, L. H.; Bottius, E.; Olivo-Marin, J. C. \& Scherf, A. 2002. A central role for Plasmodium falciparum subtelomeric regions in spatial positioning and telomere length regulation. EMBO Journal 21: 815-824.

Figueiredo, L. M. \& Cross, G. A. M. 2010. Nucleosomes are depleted at the VSG expression site transcribed by RNA polymerase I in African trypanosomes. Eukaryot Cell 9: 148-154.

Foss, M.; McNally, F. J.; Laurenson, P. \& Rine, J. 1993. Origin recognition complex (ORC) in transcriptional silencing and DNA replication in S. cerevisiae. Science 262: 18381844.

Fourel, G.; Revardel, E.; Koering, C. E. \& Gilson, E. 1999. Cohabitation of insulators and silencing elements in yeast subtelomeric regions. Embo J 18: 2522-2537.

Frank, M.; Dzikowski, R.; Costantini, D.; Amulic, B.; Berdougo, E. et al. 2006. Strict pairing of var promoters and introns is required for var gene silencing in the malaria parasite Plasmodium falciparum. J Biol Chem 281: 9942-9952.

Freitas-Junior, L. H.; Hernandez-Rivas, R.; Ralph, S. A.; Montiel-Condado, D.; RuvalcabaSalazar, O. K. et al. 2005. Telomeric heterochromatin propagation and histone acetylation control mutually exclusive expression of antigenic variation genes in malaria parasites. Cell 121: 25-36.

Frydrychova, R. C.; Mason, J. M. \& Archer, T. K. 2008. HP1 is distributed within distinct chromatin domains at Drosophila telomeres. Genetics 180: 121-131.

Gardner, M. J.; Hall, N.; Fung, E.; White, O.; Berriman, M. et al. 2002. Genome sequence of the human malaria parasite Plasmodium falciparum. Nature 419: 498-511.

Gartenberg, M. R.; Neumann, F. R.; Laroche, T.; Blaszczyk, M. \& Gasser, S. M. 2004. Sirmediated repression can occur independently of chromosomal and subnuclear contexts. Cell 119: 955-967.

Gehring, W. J.; Klemenz, R.; Weber, U. \& Kloter, U. 1984. Functional analysis of the white gene of Drosophila by P-factor-mediated transformation. EMBO J 3: 2077-2085.

Giraldo, R. \& Rhodes, D. 1994. The yeast telomere-binding protein RAP1 binds to and promotes the formation of DNA quadruplexes in telomeric DNA. Embo J 13: 24112420 . 
Glover, J. N.; Williams, R. S. \& Lee, M. S. 2004. Interactions between BRCT repeats and phosphoproteins: tangled up in two. Trends Biochem Sci 29: 579-585.

Glover, L.; Alsford, S.; Beattie, C. \& Horn, D. 2007. Deletion of a trypanosome telomere leads to loss of silencing and progressive loss of terminal DNA in the absence of cell cycle arrest. Nuc Acids Res 35: 872-880.

Glover, L. \& Horn, D. 2006. Repression of polymerase I-mediated gene expression at Trypanosoma brucei telomeres. EMBO Rep 7: 93-99.

Gotta, M.; Laroche, T.; Formenton, A.; Maillet, L.; Scherthan, H. et al. 1996. The clustering of telomeres and colocalization with Rap1, Sir3, and Sir4 proteins in wild-type Saccharomyces cerevisiae. Journal of Cell Biology 134: 1349-1363.

Gottschling, D. E.; Aparicio, O. M.; Billington, B. L. \& Zakian, V. A. 1990. Position effect at S. cerevisiae telomeres: reversible repression of pol II transcription. Cell 63: 751-762.

Graham, S. V.; Wymer, B. \& Barry, J. D. 1998. Activity of a trypanosome metacyclic variant surface glycoprotein gene promoter is dependent upon life cycle stage and chromosomal context. Molecular \& Cellular Biology 18: 1137-1146.

Grandin, N.; Reed, S. I. \& Charbonneau, M. 1997. Stn1, a new Saccharomyces cerevisiae protein, is implicated in telomere size regulation in association with cdc13. Genes $\mathcal{E}$ Development 11: 512-527.

Grandin, N.; Damon, C. \& Charbonneau, M. 2001. Ten1 functions in telomere end protection and length regulation in association with Stn1 and Cdc13. Embo J 20: 1173-1183.

Greider, C. W. \& Blackburn, E. H. 1987. The telomere terminal transferase of Tetrahymena is a ribonucleoprotein enzyme with two kinds of primer specificity. Cell 51: 887-898.

Grewal, S. I. \& Jia, S. 2007. Heterochromatin revisited. Nat Rev Genet 8: 35-46.

Griffith, J. D.; Comeau, L.; Rosenfield, S.; Stansel, R. M.; Bianchi, A. et al. 1999. Mammalian telomeres end in a large duplex loop. Cell 97: 503-514.

Grobelny, J. V.; Godwin, A. K. \& Broccoli, D. 2000. ALT-associated PML bodies are present in viable cells and are enriched in cells in the $\mathrm{G}(2) / \mathrm{M}$ phase of the cell cycle. J Cell Sci 113 Pt 24: 4577-4585.

Gunzl, A.; Bruderer, T.; Laufer, G.; Schimanski, B.; Tu, L. C. et al. 2003. RNA polymerase I transcribes procyclin genes and variant surface glycoprotein gene expression sites in Trypanosoma brucei. Eukaryot Cell 2: 542-551.

Hall, I. M.; Shankaranarayana, G. D.; Noma, K.; Ayoub, N.; Cohen, A. et al. 2002. Establishment and maintenance of a heterochromatin domain. Science 297: 22322237.

Halme, A.; Bumgarner, S.; Styles, C. \& Fink, G. R. 2004. Genetic and epigenetic regulation of the FLO gene family generates cell-surface variation in yeast. Cell 116: 405-415.

Hanaoka, S.; Nagadoi, A.; Yoshimura, S.; Aimoto, S.; Li, B. et al. 2001. NMR structure of the hRap1 Myb motif reveals a canonical three-helix bundle lacking the positive surface charge typical of Myb DNA-binding domains. J Mol Biol 312: 167-175.

Hande, M. P.; Samper, E.; Lansdorp, P. \& Blasco, M. A. 1999. Telomere length dynamics and chromosomal instability in cells derived from telomerase null mice. J Cell Biol 144: 589-601.

Hartley, C. L. \& McCulloch, R. 2008. Trypanosoma brucei BRCA2 acts in antigenic variation and has undergone a recent expansion in BRC repeat number that is important during homologous recombination. Mol Microbiol 68: 1237-1251. 
Hazelrigg, T.; Levis, R. \& Rubin, G. M. 1984. Transformation of white locus DNA in drosophila: dosage compensation, zeste interaction, and position effects. Cell 36: 469-481.

Hecht, A.; Laroche, T.; Strahl-Bolsinger, S.; Gasser, S. M. \& Grunstein, M. 1995. Histone H3 and H4 N-termini interact with SIR3 and SIR4 proteins: A molecular model for the formation of heterochromatin in yeast. Cell 80: 583-592.

Hecht, A.; Strahl-Bolsinger, S. \& Grunstein, M. 1996. Spreading of transcriptional repressor SIR3 from telomeric heterochromatin. Nature 383: 92-96.

Hertz-Fowler, C.; Figueiredo, L. M.; Quail, M. A.; Becker, M.; Jackson, A. et al. 2008. Telomeric expression sites are highly conserved in Trypanosoma brucei. PLoS ONE 3: e3527.

Holloman, W. K. 2011. Unraveling the mechanism of BRCA2 in homologous recombination. Nat Struct Mol Biol 18: 748-754.

Holthausen, J. T.; Wyman, C. \& Kanaar, R. 2010. Regulation of DNA strand exchange in homologous recombination. DNA Repair (Amst) 9: 1264-1272.

Hong, S. T.; Steele, P. E.; Cushion, M. T.; Walzer, P. D.; Stringer, S. L. et al. 1990. Pneumocystis carinii karyotypes. J Clin Microbiol 28: 1785-1795.

Hoppe, G. J.; Tanny, J. C.; Rudner, A. D.; Gerber, S. A.; Danaie, S. et al. 2002. Steps in assembly of silent chromatin in yeast: Sir3-independent binding of a Sir2/Sir4 complex to silencers and role for Sir2-dependent deacetylation. Mol. Cell. Biol. 22: 4167-4180.

Horn, D. \& McCulloch, R. 2010. Molecular mechanisms underlying the control of antigenic variation in African trypanosomes. Curr Opin Microbiol 13: 700-705.

Horn, D. \& Cross, G. A. M. 1997. Position-dependent and promoter-specific regulation of gene expression in Trypanosoma brucei. EMBO J 16: 7422-7431.

- - - . 1997. Analysis of Trypanosoma brucei vsg expression site switching in vitro. Mol. Biochem. Parasitol. 84: 189-201.

Horn, D.; Spence, C. \& Ingram, A. K. 2000. Telomere maintenance and length regulation in Trypanosoma brucei. EMBO J. 19: 2332-2339.

Houghtaling, B. R.; Cuttonaro, L.; Chang, W. \& Smith, S. 2004. A Dynamic Molecular Link between the Telomere Length Regulator TRF1 and the Chromosome End Protector TRF2. Curr Biol 14: 1621-1631.

Hughes, K.; Wand, M.; Foulston, L.; Young, R.; Harley, K. et al. 2007. A novel ISWI is involved in VSG expression site downregulation in African trypanosomes. EMBO J 26: $2400-2410$.

Ijdo, J. W.; Lindsay, E. A.; Wells, R. A. \& Baldini, A. 1992. Multiple variants in subtelomeric regions of normal karyotypes. Genomics 14: 1019-1025.

Imai, S.; Armstrong, C. M.; Kaeberlein, M. \& Guarente, L. 2000. Transcriptional silencing and longevity protein Sir2 is an NAD- dependent histone deacetylase. Nature 403: 795-800.

Iraqui, I.; Garcia-Sanchez, S.; Aubert, S.; Dromer, F.; Ghigo, J. M. et al. 2005. The Yak1p kinase controls expression of adhesins and biofilm formation in Candida glabrata in a Sir4p-dependent pathway. Mol Microbiol 55: 1259-1271.

Janzen, C. J.; Hake, S. B.; Lowell, J. E. \& Cross, G. A. 2006. Selective di- or trimethylation of histone $\mathrm{H} 3$ lysine 76 by two DOT1 homologs is important for cell cycle regulation in Trypanosoma brucei. Mol Cell 23: 497-507. 
Johnson, A.; Li, G.; Sikorski, T. W.; Buratowski, S.; Woodcock, C. L. et al. 2009. Reconstitution of heterochromatin-dependent transcriptional gene silencing. Mol Cell 35: 769-781.

Johnson, P. J.; Kooter, J. M. \& Borst, P. 1987. Inactivation of transcription by UV irradiation of $T$. brucei provides evidence for a multicistronic transcription unit including a VSG gene. Cell 51: 273-281.

Kanoh, J.; Sadaie, M.; Urano, T. \& Ishikawa, F. 2005. Telomere binding protein Taz1 establishes Swi6 heterochromatin independently of RNAi at telomeres. Curr Biol 15: 1808-1819.

Kanoh, J. \& Ishikawa, F. 2001. spRap1 and spRif1, recruited to telomeres by Taz1, are essential for telomere function in fission yeast. Curr Biol 11: 1624-1630.

Kapteyn, J. C.; Van Den Ende, H. \& Klis, F. M. 1999. The contribution of cell wall proteins to the organization of the yeast cell wall. Biochim Biophys Acta 1426: 373-383.

Karpen, G. H. \& Spradling, A. C. 1992. Analysis of subtelomeric heterochromatin in the Drosophila minichromosome Dp1187 by single P element insertional mutagenesis. Genetics 132: 737-753.

Kaur, R.; Domergue, R.; Zupancic, M. L. \& Cormack, B. P. 2005. A yeast by any other name: Candida glabrata and its interaction with the host. Curr Opin Microbiol 8: 378-384.

Kaviratne, M.; Khan, S. M.; Jarra, W. \& Preiser, P. R. 2002. Small variant STEVOR antigen is uniquely located within Maurer's clefts in Plasmodium falciparum-infected red blood cells. Eukaryot Cell 1: 926-935.

Keely, S. P.; Renauld, H.; Wakefield, A. E.; Cushion, M. T.; Smulian, A. G. et al. 2005. Gene arrays at Pneumocystis carinii telomeres. Genetics 170: 1589-1600.

Keely, S. P. \& Stringer, J. R. 2009. Complexity of the MSG gene family of Pneumocystis carinii. BMC Genomics 10: 367.

Khattab, A. \& Meri, S. 2011. Exposure of the Plasmodium falciparum clonally variant STEVOR proteins on the merozoite surface. Malar J 10: 58.

Kim, H. S. \& Cross, G. A. M. 2010. TOPO3alpha influences antigenic variation by monitoring expression-site-associated VSG switching in Trypanosoma brucei. PLoS Pathog 6: e1000992.

Kim, H. S. \& Cross, G. A. 2011. Identification of Trypanosoma brucei RMI1/BLAP75 homologue and its roles in antigenic variation. PLoS One 6: e25313.

Kim, S. H.; Kaminker, P. \& Campisi, J. 1999. TIN2, a new regulator of telomere length in human cells. Nat Genet 23: 405-412.

Kimura, A.; Umehara, T. \& Horikoshi, M. 2002. Chromosomal gradient of histone acetylation established by Sas $2 p$ and Sir2p functions as a shield against gene silencing. Nat Genet 32: 370-377.

Koering, C. E.; Pollice, A.; Zibella, M. P.; Bauwens, S.; Puisieux, A. et al. 2002. Human telomeric position effect is determined by chromosomal context and telomeric chromatin integrity. EMBO Rep 3: 1055-1061.

Konig, P.; Giraldo, R.; Chapman, L. \& Rhodes, D. 1996. The crystal structure of the DNAbinding domain of yeast RAP1 in complex with telomeric DNA. Cell 85: 125-136.

Kraemer, S. M. \& Smith, J. D. 2003. Evidence for the importance of genetic structuring to the structural and functional specialization of the Plasmodium falciparum var gene family. Mol Microbiol 50: 1527-1538. 
Krogan, N. J.; Dover, J.; Khorrami, S.; Greenblatt, J. F.; Schneider, J. et al. 2002. COMPASS, a histone H3 (Lysine 4) methyltransferase required for telomeric silencing of gene expression. J Biol Chem 277: 10753-10755.

Kyes, S. A.; Rowe, J. A.; Kriek, N. \& Newbold, C. I. 1999. Rifins: a second family of clonally variant proteins expressed on the surface of red cells infected with Plasmodium falciparum. Proc Natl Acad Sci U S A 96: 9333-9338.

Kyrion, G.; Liu, K.; Liu, C. \& Lustig, A. J. 1993. RAP1 and telomere structure regulate telomere position effects in Saccharomyces cerevisiae. Genes Dev 7: 1146-1159.

Labandeira-Rey, M. \& Skare, J. T. 2001. Decreased infectivity in Borrelia burgdorferi strain B31 is associated with loss of linear plasmid 25 or 28-1. Infect Immun 69: 446-455.

Lacoste, N.; Utley, R. T.; Hunter, J. M.; Poirier, G. G. \& Cote, J. 2002. Disruptor of telomeric silencing-1 is a chromatin-specific histone H3 methyltransferase. J Biol Chem 277: 30421-30424.

Landry, J.; Sutton, A.; Tafrov, S. T.; Heller, R. C.; Stebbins, J. et al. 2000. The silencing protein SIR2 and its homologs are NAD-dependent protein deacetylases. Proceedings of the National Academy of Sciences of the United States of America 97: 5807-5811.

Laroche, T.; Martin, S. G.; Gotta, M.; Gorham, H. C.; Pryde, F. E. et al. 1998. Mutation of yeast $\mathrm{Ku}$ genes disrupts the subnuclear organization of telomeres. Curr Biol 8: 653656.

Lavstsen, T.; Salanti, A.; Jensen, A. T.; Arnot, D. E. \& Theander, T. G. 2003. Sub-grouping of Plasmodium falciparum 3D7 var genes based on sequence analysis of coding and non-coding regions. Malar J 2: 27.

Le, S.; Moore, J. K.; Haber, J. E. \& Greider, C. W. 1999. RAD50 and RAD51 define two pathways that collaborate to maintain telomeres in the absence of telomerase. Genetics 152: 143-152.

Lebrun, E.; Revardel, E.; Boscheron, C.; Li, R.; Gilson, E. et al. 2001. Protosilencers in Saccharomyces cerevisiae subtelomeric regions. Genetics 158: 167-176.

Lenardo, M. J.; Rice-Ficht, A. C.; Kelly, G.; Esser, K. M. \& Donelson, J. E. 1984. Characterization of the genes specifying two metacyclic variable antigen types in Trypanosoma brucei rhodesiense. PNAS 81: 6642-6646.

Lendvay, T. S.; Morris, D. K.; Sah, J.; Balasubramanian, B. \& Lundblad, V. 1996. Senescence mutants of Saccharomyces cerevisiae with a defect in telomere replication identify three additional EST genes. Genetics 144: 1399-1412.

Levis, R.; Hazelrigg, T. \& Rubin, G. M. 1985. Effects of genomic position on the expression of transduced copies of the white gene of Drosophila. Science 229: 558-561.

Levis, R. W.; Ganesan, R.; Houtchens, K.; Tolar, L. A. \& Sheen, F. M. 1993. Transposons in place of telomeric repeats at a Drosophila telomere. Cell 75: 1083-1093.

Levy, M. Z.; Allsopp, R. C.; Futcher, A. B.; Greider, C. W. \& Harley, C. B. 1992. Telomere end-replication problem and cell aging. J Mol Biol 225: 951-960.

Li, B.; Oestreich, S. \& de Lange, T. 2000. Identification of human Rap1: implications for telomere evolution. Cell 101: 471-483.

Li, B.; Espinal, A. \& Cross, G. A. M. 2005. Trypanosome telomeres are protected by a homologue of mammalian TRF2. Mol Cell Biol 25: 5011-5021.

Li, B. \& Lustig, A. J. 1996. A novel mechanism for telomere size control in Saccharomyces cerevisiae. Genes Dev 10: 1310-1326. 
Liang, X. H.; Haritan, A.; Uliel, S. \& Michaeli, S. 2003. trans and cis splicing in trypanosomatids: mechanism, factors, and regulation. Eukaryot Cell 2: 830-840.

Lieb, J. D.; Liu, X.; Botstein, D. \& Brown, P. O. 2001. Promoter-specific binding of Rap1 revealed by genome-wide maps of protein-DNA association. Nat Genet 28: 327-334.

Linardopoulou, E. V.; Williams, E. M.; Fan, Y.; Friedman, C.; Young, J. M. et al. 2005. Human subtelomeres are hot spots of interchromosomal recombination and segmental duplication. Nature 437: 94-100.

Liu, C.; Mao, X. \& Lustig, A. J. 1994. Mutational analysis defines a C-terminal tail domain of RAP1 essential for telomeric silencing in Saccharomyces cerevisiae. Genetics 138: 1025-1040.

Liu, C. \& Lustig, A. J. 1996. Genetic analysis of Rap1p/Sir3p interactions in telomeric and HML silencing in Saccharomyces cerevisiae. Genetics 143: 81-93.

Liu, D.; Safari, A.; O'Connor, M. S.; Chan, D. W.; Laegeler, A. et al. 2004. PTOP interacts with POT1 and regulates its localization to telomeres. Nat Cell Biol 6: 673-680.

Londono-Vallejo, J. A.; Der-Sarkissian, H.; Cazes, L.; Bacchetti, S. \& Reddel, R. R. 2004. Alternative lengthening of telomeres is characterized by high rates of telomeric exchange. Cancer Res 64: 2324-2327.

Loney, E. R.; Inglis, P. W.; Sharp, S.; Pryde, F. E.; Kent, N. A. et al. 2009. Repressive and nonrepressive chromatin at native telomeres in Saccharomyces cerevisiae. Epigenetics Chromatin 2: 18.

Longtine, M. S.; Wilson, N. M.; Petracek, M. E. \& Berman, J. 1989a. A yeast telomere binding activity binds to two related telomere sequence motifs and is indistinguishable from RAP1. Curr. Genet. 16: 225-239.

Longtine, M. S.; Wilson, N. M.; Petracek, M. E. \& Berman, J. 1989b. A yeast telomere binding activity binds to two related telomere sequence motifs and is indistinguishable from RAP1. Curr Genet 16: 225-239.

Lopez-Rubio, J. J.; Gontijo, A. M.; Nunes, M. C.; Issar, N.; Hernandez Rivas, R. et al. 2007. 5' flanking region of var genes nucleate histone modification patterns linked to phenotypic inheritance of virulence traits in malaria parasites. Mol Microbiol 66: 1296-1305.

Louis, E. J. \& Haber, J. E. 1991. Evolutionarily recent transfer of a group I mitochondrial intron to telomere regions in Saccharomyces cerevisiae. Curr Genet 20: 411-415.

- - - . 1992. The structure and evolution of subtelomeric $Y^{\prime}$ repeats in Saccharomyces cerevisiae. Genetics 131: 559-574.

Louis, E. J.; Naumova, E. S.; Lee, A.; Naumov, G. \& Haber, J. E. 1994. The chromosome end in yeast: its mosaic nature and influence on recombinational dynamics. Genetics 136: 789-802.

Louis, E. J. 1995. The chromosome ends of Saccharomyces cerevisiae. Yeast 11: 1553-1573.

Lundblad, V. \& Szostak, J. W. 1989. A mutant with a defect in telomere elongation leads to senescence in yeast. Cell 57: 633-643.

Lundblad, V. \& Blackburn, E. H. 1993. An alternative pathway for yeast telomere maintenance rescues est1- senescence. Cell 73: 347-360.

Luo, K.; Vega-Palas, M. A. \& Grunstein, M. 2002. Rap1-Sir4 binding independent of other Sir, $\mathrm{yKu}$, or histone interactions initiates the assembly of telomeric heterochromatin in yeast. Genes Dev 16: 1528-1539. 
Mankouri, H. W. \& Hickson, I. D. 2007. The RecQ helicase-topoisomerase III-Rmi1 complex: a DNA structure-specific 'dissolvasome'? Trends Biochem Sci 32: 538-546.

Marahrens, Y. \& Stillman, B. 1992. A yeast chromosomal origin of DNA replication defined by multiple functional elements. Science 255: 817-823.

Marcello, L. \& Barry, J. D. 2007. Analysis of the VSG gene silent archive in Trypanosoma brucei reveals that mosaic gene expression is prominent in antigenic variation and is favored by archive substructure. Genome Res 17: 1344-1352.

Martin, S. G.; Laroche, T.; Suka, N.; Grunstein, M. \& Gasser, S. M. 1999. Relocalization of telomeric $\mathrm{Ku}$ and SIR proteins in response to DNA strand breaks in yeast. Cell 97: 621-633.

Martinez, P.; Thanasoula, M.; Carlos, A. R.; Gomez-Lopez, G.; Tejera, A. M. et al. 2010. Mammalian Rap1 controls telomere function and gene expression through binding to telomeric and extratelomeric sites. Nat Cell Biol

Martino, F.; Kueng, S.; Robinson, P.; Tsai-Pflugfelder, M.; van Leeuwen, F. et al. 2009. Reconstitution of yeast silent chromatin: multiple contact sites and O-AADPR binding load SIR complexes onto nucleosomes in vitro. Mol Cell 33: 323-334.

Mason, J. M.; Konev, A. Y.; Golubovsky, M. D. \& Biessmann, H. 2003. Cis- and trans-acting influences on telomeric position effect in Drosophila melanogaster detected with a subterminal transgene. Genetics 163: 917-930.

Matthews, K. R. 2005. The developmental cell biology of Trypanosoma brucei. J Cell Sci 118: 283-290.

McCulloch, R. \& Barry, J. D. 1999. A role for RAD51 and homologous recombination in Trypanosoma brucei antigenic variation. Genes \& Development 13: 2875-2888.

McEachern, M. J. \& Blackburn, E. H. 1996. Cap-prevented recombination between terminal telomeric repeat arrays (telomere CPR) maintains telomeres in Kluyveromyces lactis lacking telomerase. Genes Dev 10: 1822-1834.

McEachern, M. J. \& J. E. Haber. 2006. Telomerase-independent Telomere Maintenance in Yeast. In Telomeres. Edited by de lange, T.; V. Lundblad \& E. H. Blackburn. Cold Spring Harbor Laboratory Press, Cold Spring Harbor, New York, pp 199-224.

Mefford, H. C. \& Trask, B. J. 2002. The complex structure and dynamic evolution of human subtelomeres. Nat Rev Genet 3: 91-102.

Mehlert, A.; Zitzmann, N.; Richardson, J. M.; Treumann, A. \& Ferguson, M. A. J. 1998. The glycosylation of the variant surface glycoproteins and procyclic acidic repetitive proteins of Trypanosoma brucei. Molecular \& Biochemical Parasitology 91: 145-152.

Melville, S. E.; Leech, V.; Navarro, M. \& Cross, G. A. M. 2000. The molecular karyotype of the megabase chromosomes of Trypanosoma brucei stock 427. Mol. Biochem. Parasitol. 111: 261-273.

Merrick, C. J. \& Duraisingh, M. T. 2007. Plasmodium falciparum Sir2: an unusual sirtuin with dual histone deacetylase and ADP-ribosyltransferase activity. Eukaryot Cell 6: 2081-2091.

Micklem, G.; Rowley, A.; Harwood, J.; Nasmyth, K. \& Diffley, J. F. 1993. Yeast origin recognition complex is involved in DNA replication and transcriptional silencing. Nature 366: 87-89.

Miyake, Y.; Nakamura, M.; Nabetani, A.; Shimamura, S.; Tamura, M. et al. 2009. RPA-like mammalian Ctc1-Stn1-Ten1 complex binds to single-stranded DNA and protects telomeres independently of the Pot1 pathway. Mol Cell 36: 193-206. 
Moazed, D.; Kistler, A.; Axelrod, A.; Rine, J. \& Johnson, A. D. 1997. Silent information regulator protein complexes in Saccharomyces cerevisiae - a sir2/sir4 complex and evidence for a regulatory domain in sir4 that inhibits its interaction with sir3. Proceedings of the National Academy of Sciences of the United States of America 94: 21862191.

Mok, B. W.; Ribacke, U.; Rasti, N.; Kironde, F.; Chen, Q. et al. 2008. Default Pathway of var2csa switching and translational repression in Plasmodium falciparum. PLoS One 3: e1982.

Moretti, P.; Freeman, K.; Coodly, L. \& Shore, D. 1994. Evidence that a complex of SIR proteins interacts with the silencer and telomere-binding protein RAP1. Genes Dev 8: 2257-2269.

Moretti, P. \& Shore, D. 2001. Multiple interactions in sir protein recruitment by Rap1p at silencers and telomeres in yeast. Molecular and Cellular Biology 21: 8082-8094.

Mottram, J. C.; Murphy, W. J. \& Agabian, N. 1989. A transcriptional analysis of the Trypanosoma brucei hsp83 gene cluster. MBP 37: 115-127.

Munoz-Jordan, J. L. \& Cross, G. A. M. 2001. Telomere shortening and cell cycle arrest in Trypanosoma brucei expressing human telomeric repeat factor TRF1. Mol. Biochem. Parasitol. 114: 169-181.

Munoz-Jordan, J. L.; Cross, G. A. M.; de Lange, T. \& Griffith, J. D. 2001. t-loops at trypanosome telomeres. EMBO J 20: 579-588.

Murnane, J. P.; Sabatier, L.; Marder, B. A. \& Morgan, W. F. 1994. Telomere dynamics in an immortal human cell line. Embo J 13: 4953-4962.

Murray, A. W. \& J. W. Szostak. 1983. Construction of artificial chromosomes in yeast. In 305 189-305 193.

Murti, K. G. \& Prescott, D. M. 1999. Telomeres of polytene chromosomes in a ciliated protozoan terminate in duplex DNA loops. Proc Natl Acad Sci U S A 96: 1443614439.

Myler, P. J.; Aline, R. F. J.; Scholler, J. K. \& Stuart, K. D. 1988. Changes in telomere length associated with antigenic variation in Trypanosoma brucei. MBP 29: 243-250.

Nabetani, A. \& Ishikawa, F. 2011. Alternative lengthening of telomeres pathway: recombination-mediated telomere maintenance mechanism in human cells. $J$ Biochem 149: 5-14.

Nagy, P. L.; Griesenbeck, J.; Kornberg, R. D. \& Cleary, M. L. 2002. A trithorax-group complex purified from Saccharomyces cerevisiae is required for methylation of histone H3. Proc Natl Acad Sci U S A 99: 90-94.

Nakayama, J.; Rice, J. C.; Strahl, B. D.; Allis, C. D. \& Grewal, S. I. 2001. Role of histone H3 lysine 9 methylation in epigenetic control of heterochromatin assembly. Science 292: 110-113.

Naumov, G. I.; Naumova, E. S.; Turakainen, H. \& Korhola, M. 1992. A new family of polymorphic metallothionein-encoding genes MTH1 (CUP1) and MTH2 in Saccharomyces cerevisiae. Gene 119: 65-74.

Navarro, M. \& Gull, K. 2001. A pol I transcriptional body associated with VSG mono-allelic expression in Trypanosoma brucei. Nature 414: 759-763.

Ness, F. \& Aigle, M. 1995. RTM1: a member of a new family of telomeric repeated genes in yeast. Genetics 140: 945-956. 
Ng, H. H.; Feng, Q.; Wang, H.; Erdjument-Bromage, H.; Tempst, P. et al. 2002. Lysine methylation within the globular domain of histone $\mathrm{H} 3$ by Dot1 is important for telomeric silencing and Sir protein association. Genes Dev 16: 1518-1527.

Niida, H.; Shinkai, Y.; Hande, M. P.; Matsumoto, T.; Takehara, S. et al. 2000. Telomere maintenance in telomerase-deficient mouse embryonic stem cells: characterization of an amplified telomeric DNA. Mol Cell Biol 20: 4115-4127.

Nikitina, T. \& Woodcock, C. L. 2004. Closed chromatin loops at the ends of chromosomes. J Cell Biol 166: 161-165.

Noma, K.; Sugiyama, T.; Cam, H.; Verdel, A.; Zofall, M. et al. 2004. RITS acts in cis to promote RNA interference-mediated transcriptional and post-transcriptional silencing. Nat Genet 36: 1174-1180.

Norris, S. J. 2006. Antigenic variation with a twist--the Borrelia story. Mol Microbiol 60: 13191322.

Nugent, C. I.; Hughes, T. R.; Lue, N. F. \& Lundblad, V. 1996. Cdc13p: a single-strand telomeric DNA-binding protein with a dual role in yeast telomere maintenance. Science 274: 249-252.

O'Connor, M. S.; Safari, A.; Liu, D.; Qin, J. \& Songyang, Z. 2004. The human Rap1 protein complex and modulation of telomere length. J Biol Chem 279: 28585-28591.

Opitz, O. G.; Suliman, Y.; Hahn, W. C.; Harada, H.; Blum, H. E. et al. 2001. Cyclin D1 overexpression and p53 inactivation immortalize primary oral keratinocytes by a telomerase-independent mechanism. J Clin Invest 108: 725-732.

Palm, W. \& de Lange, T. 2008. How shelterin protects mammalian telomeres. Annu Rev Genet 42: 301-334.

Pardue, M. L. \& DeBaryshe, P. G. 2008. Drosophila telomeres: A variation on the telomerase theme. Fly (Austin) 2: 101-110.

Park, M. J.; Jang, Y. K.; Choi, E. S.; Kim, H. S. \& Park, S. D. 2002. Fission yeast Rap1 homolog is a telomere-specific silencing factor and interacts with Taz1p. Mol Cells 13: 327333.

Pays, E.; Laurent, M.; Delinte, K.; Van Meirvenne, N. \& Steinert, M. 1983a. Differential size variations between transcriptionally active and inactive telomeres of Trypanosoma brucei. Nucleic Acids Res 11: 8137-8147.

Pays, E.; van Assel, S.; Laurent, M.; Dero, B.; Michiels, F. et al. 1983b. At least two transposed sequences are associated in the expression site of a surface antigen gene in different trypanosome clones. Cell 34: 359-369.

Pedram, M.; Sprung, C. N.; Gao, Q.; Lo, A. W.; Reynolds, G. E. et al. 2006. Telomere position effect and silencing of transgenes near telomeres in the mouse. Mol Cell Biol 26: 1865-1878.

Pedram, M. \& Donelson, J. E. 1999. The anatomy and transcription of a monocistronic expression site for a metacyclic variant surface glycoprotein gene in Trypanosoma brucei. J Biol Chem 274: 16876-16883.

Petrie, V. J.; Wuitschick, J. D.; Givens, C. D.; Kosinski, A. M. \& Partridge, J. F. 2005. RNA interference (RNAi)-dependent and RNAi-independent association of the Chp1 chromodomain protein with distinct heterochromatic loci in fission yeast. Mol Cell Biol 25: 2331-2346.

Pham, V. P.; Qi, C. C. \& Gottesdiener, K. M. 1996. A detailed mutational analysis of the VSG gene expression site promoter. Mol Biochem Parasitol 75: 241-254. 
Pizzi, E. \& Frontali, C. 2001. Fine structure of Plasmodium falciparum subtelomeric sequences. Mol. Biochem. Parasitol. 118: 253-258.

Pologe, L. G. \& Ravetch, J. V. 1988. Large deletions result from breakage and healing of P. falciparum chromosomes. Cell 55: 869-874.

Proudfoot, C. \& McCulloch, R. 2005. Distinct roles for two RAD51-related genes in Trypanosoma brucei antigenic variation. Nucleic Acids Res 33: 6906-6919.

Pryde, F. E. \& Louis, E. J. 1999. Limitations of silencing at native yeast telomeres. EMBO J. 18: $2538-2550$.

Purser, J. E. \& Norris, S. J. 2000. Correlation between plasmid content and infectivity in Borrelia burgdorferi. Proc Natl Acad Sci U S A 97: 13865-13870.

Ralph, S. A.; Scheidig-Benatar, C. \& Scherf, A. 2005. Antigenic variation in Plasmodium falciparum is associated with movement of var loci between subnuclear locations. Proc Natl Acad Sci U S A 102: 5414-5419.

Ralph, S. A. \& Scherf, A. 2005. The epigenetic control of antigenic variation in Plasmodium falciparum. Curr Opin Microbiol 8: 434-440.

Rao, H.; Marahrens, Y. \& Stillman, B. 1994. Functional conservation of multiple elements in yeast chromosomal replicators. Mol Cell Biol 14: 7643-7651.

Reddel, R. R.; Bryan, T. M. \& Murnane, J. P. 1997. Immortalized cells with no detectable telomerase activity. A review. Biochemistry (Mosc) 62: 1254-1262.

Reifsnyder, C.; Lowell, J.; Clarke, A. \& Pillus, L. 1996. Yeast SAS silencing genes and human genes associated with AML and HIV-1 Tat interactions are homologous with acetyltransferases. Nat Genet 14: 42-49.

Renauld, H.; Aparicio, O. M.; Zierath, P. D.; Billington, B. L.; Chhablani, S. K. et al. 1993. Silent domains are assembled continuously from the telomere and are defined by promoter distance and strength, and by SIR3 dosage. Genes Dev 7: 1133-1145.

Reynolds, T. B. \& Fink, G. R. 2001. Bakers' yeast, a model for fungal biofilm formation. Science 291: 878-881.

Riha, K.; Heacock, M. L. \& Shippen, D. E. 2006. The role of the nonhomologous end-joining DNA double-strand break repair pathway in telomere biology. Annu Rev Genet 40: 237-277.

Roberts, D. J.; Craig, A. G.; Berendt, A. R.; Pinches, R.; Nash, G. et al. 1992. Rapid switching to multiple antigenic and adhesive phenotypes in malaria. Nature 357: 689-692.

Robinson, N. P.; Burman, N.; Melville, S. E. \& Barry, J. D. 1999. Predominance of duplicative VSG gene conversion in antigenic variation in African trypanosomes. Mol Cell Biol 19: 5839-5846.

Roguev, A.; Schaft, D.; Shevchenko, A.; Pijnappel, W. W.; Wilm, M. et al. 2001. The Saccharomyces cerevisiae Set1 complex includes an Ash2 homologue and methylates histone 3 lysine 4. EMBO J 20: 7137-7148.

Rubio, J. P.; Thompson, J. K. \& Cowman, A. F. 1996. The var genes of Plasmodium falciparum are located in the subtelomeric region of most chromosomes. EMBO Journal 15: 4069-4077.

Rudenko, G. \& Van der Ploeg, L. H. 1989. Transcription of telomere repeats in protozoa. Embo J 8: 2633-2638.

Rudenko, G.; McCulloch, R.; Dirksmulder, A. \& Borst, P. 1996. Telomere exchange can be an important mechanism of variant surface glycoprotein gene switching in Trypanosoma brucei. Molecular \& Biochemical Parasitology 80: 65-75. 
Rusche, L. N.; Kirchmaier, A. L. \& Rine, J. 2002. Ordered nucleation and spreading of silenced chromatin in Saccharomyces cerevisiae. Mol Biol Cell 13: 2207-2222.

Sadaie, M.; Iida, T.; Urano, T. \& Nakayama, J. 2004. A chromodomain protein, Chp1, is required for the establishment of heterochromatin in fission yeast. EMBO J 23: 38253835 .

Salanti, A.; Staalsoe, T.; Lavstsen, T.; Jensen, A. T.; Sowa, M. P. et al. 2003. Selective upregulation of a single distinctly structured var gene in chondroitin sulphate Aadhering Plasmodium falciparum involved in pregnancy-associated malaria. Mol Microbiol 49: 179-191.

Scherf, A.; Figueiredo, L. M. \& Freitas-Junior, L. H. 2001. Plasmodium telomeres: a pathogen's perspective. Current Opinion in Microbiology 4: 409-414.

Schwan, T. G.; Karstens, R. H.; Schrumpf, M. E. \& Simpson, W. J. 1991. Changes in antigenic reactivity of Borrelia burgdorferi, the Lyme disease spirochete, during persistent infection in mice. Can J Microbiol 37: 450-454.

Serizawa, S.; Miyamichi, K. \& Sakano, H. 2004. One neuron-one receptor rule in the mouse olfactory system. Trends Genet 20: 648-653.

Sfeir, A.; Kabir, S.; van Overbeek, M.; Celli, G. B. \& de Lange, T. 2010. Loss of Rap1 induces telomere recombination in the absence of NHEJ or a DNA damage signal. Science 327: 1657-1661.

Shi, H. F.; Djikeng, A.; Mark, T.; Wirtz, E.; Tschudi, C. et al. 2000. Genetic interference in Trypanosoma brucei by heritable and inducible double-stranded RNA. RNA-A Publication of the RNA Society 6: 1069-1076.

Shykind, B. M. 2005. Regulation of odorant receptors: one allele at a time. Hum Mol Genet 14 Spec No 1: R33-9.

Singer, M. S. \& Gottschling, D. E. 1994. TLC1: template RNA component of Saccharomyces cerevisiae telomerase [see comments]. Science 266: 404-409.

Smith, J. D.; Chitnis, C. E.; Craig, A. G.; Roberts, D. J.; Hudson-Taylor, D. E. et al. 1995. Switches in expression of Plasmodium falciparum var genes correlate with changes in antigenic and cytoadherent phenotypes of infected erythrocytes. Cell 82: 101-110.

Smith, J. S.; Brachmann, C. B.; Celic, I.; Kenna, M. A.; Muhammad, S. et al. 2000. A phylogenetically conserved NAD+-dependent protein deacetylase activity in the Sir2 protein family. Proc Natl Acad Sci U S A 97: 6658-6663.

Smith, S.; Banerjee, S.; Rilo, R. \& Myung, K. 2008. Dynamic regulation of single-stranded telomeres in Saccharomyces cerevisiae. Genetics 178: 693-701.

Stanne, T. M. \& Rudenko, G. 2010. Active VSG expression sites in Trypanosoma brucei are depleted of nucleosomes. Eukaryot Cell 9: 136-147.

Stanne, T. M.; Kushwaha, M.; Wand, M.; Taylor, J. E. \& Rudenko, G. 2011. TbISWI regulates multiple polymerase I (Pol I)-transcribed loci and is present at Pol II transcription boundaries in Trypanosoma brucei. Eukaryot Cell 10: 964-976.

Steere, A. C.; Coburn, J. \& Glickstein, L. 2004. The emergence of Lyme disease. J Clin Invest 113: 1093-1101.

Stewart, J. A.; Chaiken, M. F.; Wang, F. \& Price, C. M. 2011. Maintaining the end: Roles of telomere proteins in end-protection, telomere replication and length regulation. Mutat Res

Strahl-Bolsinger, S.; Hecht, A.; Luo, K. \& Grunstein, M. 1997. SIR2 and SIR4 interactions differ in core and extended telomeric heterochromatin in yeast. Genes Dev 11: 83-93. 
Strahl, B. D.; Grant, P. A.; Briggs, S. D.; Sun, Z. W.; Bone, J. R. et al. 2002. Set2 is a nucleosomal histone $\mathrm{H} 3$-selective methyltransferase that mediates transcriptional repression. Mol Cell Biol 22: 1298-1306.

Stringer, J. R. 2005. Surface antigens. In Pneumocystis Pneumonia. Edited by Walzer, P. D. \& M. T. Cushion. New York: Marcel Dekker, New York, pp 95-126.

Su, X.; Heatwole, V. M.; Wertheimer, S. P.; Guinet, F.; Herrfeldt, J. A. et al. 1995. The large diverse gene family var encodes proteins involved in cytoadherence and antigenic variation of Plasmodium falciparum-infected erythrocytes. Cell 82: 89-100.

$\mathrm{Su}$, Y.; Barton, A. B. \& Kaback, D. B. 2000. Decreased meiotic reciprocal recombination in subtelomeric regions in Saccharomyces cerevisiae. Chromosoma 109: 467-475.

Sugioka-Sugiyama, R. \& Sugiyama, T. 2011. Sde2: a novel nuclear protein essential for telomeric silencing and genomic stability in Schizosaccharomyces pombe. Biochem Biophys Res Commun 406: 444-448.

Sugiyama, T.; Cam, H. P.; Sugiyama, R.; Noma, K.; Zofall, M. et al. 2007. SHREC, an effector complex for heterochromatic transcriptional silencing. Cell 128: 491-504.

Suka, N.; Luo, K. \& Grunstein, M. 2002. Sir2p and Sas2p opposingly regulate acetylation of yeast histone H4 lysine16 and spreading of heterochromatin. Nat Genet 32: 378-383.

Sunkin, S. M. \& Stringer, J. R. 1997. Residence at the expression site is necessary and sufficient for the transcription of surface antigen genes of Pneumocystis carinii. Mol Microbiol 25: 147-160.

Sunkin, S. M.; Linke, M. J.; McCormack, F. X.; Walzer, P. D. \& Stringer, J. R. 1998. Identification of a putative precursor to the major surface glycoprotein of Pneumocystis carinii. Infect Immun 66: 741-746.

Taddei, A. \& Gasser, S. M. 2004. Multiple pathways for telomere tethering: functional implications of subnuclear position for heterochromatin formation. Biochim Biophys Acta 1677: 120-128.

Tanny, J. C.; Dowd, G. J.; Huang, J.; Hilz, H. \& Moazed, D. 1999. An enzymatic activity in the yeast Sir2 protein that is essential for gene silencing. Cell 99: 735-745.

Teng, S. C. \& Zakian, V. A. 1999. Telomere-telomere recombination is an efficient bypass pathway for telomere maintenance in Saccharomyces cerevisiae. Molecular $\mathcal{E}$ Cellular Biology 19: 8083-8093.

Teng, S. C.; Chang, J.; McCowan, B. \& Zakian, V. A. 2000. Telomerase-independent lengthening of yeast telomeres occurs by an abrupt Rad50p-dependent, Rifinhibited recombinational process. Mol Cell 6: 947-952.

Teytelman, L.; Eisen, M. B. \& Rine, J. 2008. Silent but not static: accelerated base-pair substitution in silenced chromatin of budding yeasts. PLoS Genet 4: e1000247.

Thompson, J. K.; Rubio, J. P.; Caruana, S.; Brockman, A.; Wickham, M. E. et al. 1997. The chromosomal organization of the Plasmodium falciparum var gene family is conserved. Mol Biochem Parasitol 87: 49-60.

Tompa, R. \& Madhani, H. D. 2007. Histone H3 lysine 36 methylation antagonizes silencing in Saccharomyces cerevisiae independently of the Rpd3S histone deacetylase complex. Genetics 175: 585-593.

Tonkin, C. J.; Carret, C. K.; Duraisingh, M. T.; Voss, T. S.; Ralph, S. A. et al. 2009. Sir2 paralogues cooperate to regulate virulence genes and antigenic variation in Plasmodium falciparum. PLoS Biol 7: e84.

Trask, B. J.; Friedman, C.; Martin-Gallardo, A.; Rowen, L.; Akinbami, C. et al. 1998. Members of the olfactory receptor gene family are contained in large blocks of DNA 
duplicated polymorphically near the ends of human chromosomes. Hum Mol Genet 7: 13-26.

Triolo, T. \& Sternglanz, R. 1996. Role of interactions between the origin recognition complex and SIR1 in transcriptional silencing. Nature 381: 251-253.

Tsukamoto, Y.; Kato, J. \& Ikeda, H. 1997. Silencing factors participate in DNA repair and recombination in Saccharomyces cerevisiae. Nature 388: 900-903.

Turakainen, H.; Naumov, G.; Naumova, E. \& Korhola, M. 1993. Physical mapping of the MEL gene family in Saccharomyces cerevisiae. Curr Genet 24: 461-464.

Turner, C. M. R.; Barry, J. D.; Maudlin, I. \& Vickerman, K. 1988. An estimate of the size of the metacyclic variable antigen repertoire of Trypanosoma brucei rhodensiense. Parasitology 97: 269-276.

van der Ploeg, L. H. T.; Liu, A. Y. C. \& Borst, P. 1984. Structure of the growing telomeres of trypanosomes. Cell 36: 459-468.

van Leeuwen, F.; Gafken, P. R. \& Gottschling, D. E. 2002. Dot1p modulates silencing in yeast by methylation of the nucleosome core. Cell 109: 745-756.

Van Mulders, S. E.; Christianen, E.; Saerens, S. M.; Daenen, L.; Verbelen, P. J. et al. 2009. Phenotypic diversity of Flo protein family-mediated adhesion in Saccharomyces cerevisiae. FEMS Yeast Res 9: 178-190.

Vanhamme, L.; Poelvoorde, P.; Pays, A.; Tebabi, P.; Van Xong, H. et al. 2000. Differential RNA elongation controls the variant surface glycoprotein gene expression sites of Trypanosoma brucei. Mol. Microbiol. 36: 328-340.

Venkatasubrahmanyam, S.; Hwang, W. W.; Meneghini, M. D.; Tong, A. H. \& Madhani, H. D. 2007. Genome-wide, as opposed to local, antisilencing is mediated redundantly by the euchromatic factors Set1 and H2A.Z. Proc Natl Acad Sci U S A 104: 1660916614.

Viswanathan, M.; Muthukumar, G.; Cong, Y. S. \& Lenard, J. 1994. Seripauperins of Saccharomyces cerevisiae: a new multigene family encoding serine-poor relatives of serine-rich proteins. Gene 148: 149-153.

Volpe, T. A.; Kidner, C.; Hall, I. M.; Teng, G.; Grewal, S. I. et al. 2002. Regulation of heterochromatic silencing and histone H3 lysine-9 methylation by RNAi. Science 297: 1833-1837.

Voss, T. S.; Thompson, J. K.; Waterkeyn, J.; Felger, I.; Weiss, N. et al. 2000. Genomic distribution and functional characterisation of two distinct and conserved Plasmodium falciparum var gene 5' flanking sequences. Mol Biochem Parasitol 107: 103-115.

Voss, T. S.; Healer, J.; Marty, A. J.; Duffy, M. F.; Thompson, J. K. et al. 2006. A var gene promoter controls allelic exclusion of virulence genes in Plasmodium falciparum malaria. Nature 439: 1004-1008.

Wada, M.; Sunkin, S. M.; Stringer, J. R. \& Nakamura, Y. 1995. Antigenic variation by positional control of major surface glycoprotein gene expression in Pneumocystis carinii. J Infect Dis 171: 1563-1568.

Wada, M. \& Nakamura, Y. 1996. Unique telomeric expression site of major-surfaceglycoprotein genes of Pneumocystis carinii. DNA Res 3: 55-64.

Wallrath, L. L. \& Elgin, S. C. R. 1995. Position effect variegation in Drosophila is associated with an altered chromatin structure. Genes Dev 9: 1263-1277. 
Walter, M. F.; Jang, C.; Kasravi, B.; Donath, J.; Mechler, B. M. et al. 1995. DNA organization and polymorphism of a wild-type Drosophila telomere region. Chromosoma 104: 229-241.

Wan, M.; Qin, J.; Songyang, Z. \& Liu, D. 2009. OB fold-containing protein 1 (OBFC1), a human homolog of yeast Stn1, associates with TPP1 and is implicated in telomere length regulation. J Biol Chem 284: 26725-26731.

Wang, Q. P.; Kawahara, T. \& Horn, D. 2010. Histone deacetylases play distinct roles in telomeric VSG expression site silencing in African trypanosomes. Mol Microbiol 77: 1237-1245.

Wang, R. C.; Smogorzewska, A. \& de Lange, T. 2004. Homologous recombination generates T-loop-sized deletions at human telomeres. Cell 119: 355-368.

Weaver, D.; Boubnov, N.; Wills, Z.; Hall, K. \& Staunton, J. 1995. V(D)J recombination: double-strand break repair gene products used in the joining mechanism. Ann $N Y$ Acad Sci 764: 99-111.

Wilkie, A. O.; Higgs, D. R.; Rack, K. A.; Buckle, V. J.; Spurr, N. K. et al. 1991. Stable length polymorphism of up to $260 \mathrm{~kb}$ at the tip of the short arm of human chromosome 16. Cell 64: 595-606.

Wyrick, J. J.; Holstege, F. C.; Jennings, E. G.; Causton, H. C.; Shore, D. et al. 1999. Chromosomal landscape of nucleosome-dependent gene expression and silencing in yeast. Nature 402: 418-421.

Wyrick, J. J.; Aparicio, J. G.; Chen, T.; Barnett, J. D.; Jennings, E. G. et al. 2001. Genome-wide distribution of ORC and MCM proteins in S. cerevisiae: high-resolution mapping of replication origins. Science 294: 2357-2360.

Yang, X.; Figueiredo, L. M.; Espinal, A.; Okubo, E. \& Li, B. 2009. RAP1 is essential for silencing telomeric variant surface glycoprotein genes in Trypanosoma brucei. Cell 137: 99-109.

Ye, J. Z.; Hockemeyer, D.; Krutchinsky, A. N.; Loayza, D.; Hooper, S. M. et al. 2004. POT1interacting protein PIP1: a telomere length regulator that recruits POT1 to the TIN2/TRF1 complex. Genes Dev 18: 1649-1654.

Zakian, V. A. \& Blanton, H. M. 1988. Distribution of telomere-associated sequences on natural chromosomes in Saccharomyces cerevisiae. Mol Cell Biol 8: 2257-2260.

Zhang, J. R.; Hardham, J. M.; Barbour, A. G. \& Norris, S. J. 1997. Antigenic variation in Lyme disease borreliae by promiscuous recombination of VMP-like sequence cassettes. Cell 89: 275-285.

Zhang, J. R. \& Norris, S. J. 1998a. Kinetics and in vivo induction of genetic variation of vlsE in Borrelia burgdorferi. Infect Immun 66: 3689-3697.

- - - 1998b. Genetic variation of the Borrelia burgdorferi gene vlsE involves cassettespecific, segmental gene conversion. Infect Immun 66: 3698-3704.

Zomerdijk, J. C. B. M.; Ouellete, M.; ten Asbroek, A. L. M. A.; Kieft, R.; Bommer, A. M. M. et al. 1990. The promoter for a variant surface glycoprotein gene expression site in Trypanosoma brucei. EMBO J. 9: 2791-2801.

Zomerdijk, J. C. B. M.; Kieft, R.; Duyndam, M.; Shiels, P. G. \& Borst, P. 1991. Antigenic variation in Trypanosoma brucei: a telomeric expression site for variant-specific surface glycoprotein genes with novel features. Nucl Acids Res. 19: 1359-1368.

Zvereva, M. I.; Shcherbakova, D. M. \& Dontsova, O. A. 2010. Telomerase: structure, functions, and activity regulation. Biochemistry (Mosc) 75: 1563-1583. 
(C) 2012 The Author(s). Licensee IntechOpen. This is an open access article distributed under the terms of the Creative Commons Attribution 3.0 License, which permits unrestricted use, distribution, and reproduction in any medium, provided the original work is properly cited. 